\title{
Electrophotochemical Ring-Opening Bromination of tert-Cycloalkanols
}

\author{
Kosuke Yamamoto, ${ }^{a}$ Hiroyuki Toguchi, ${ }^{a}$ Masami Kuriyama, ${ }^{a}$ Shin Watanabe, ${ }^{b}$ \\ Fumiaki Iwasaki, ${ }^{b}$ Osamu Onomura ${ }^{\text {a* }}$ \\ ${ }^{a}$ Graduate School of Biomedical Sciences, Nagasaki University, 1-14 Bunkyo-machi, \\ Nagasaki 852-8521, Japan \\ ${ }^{b}$ Tsukuba Research Laboratories, Tokuyama Corporation, 40 Wadai, Tsukuba, \\ Ibaraki 300-4247, Japan \\ *onomura@nagasaki-u.ac.jp

\section{Supporting Information}

\section{Table of Contents}

1. Experimental setup for the electrophotochemical reaction S2

2. Partial ${ }^{1} \mathrm{H}$ and ${ }^{13} \mathrm{C}\left\{{ }^{1} \mathrm{H}\right\}$ NMR spectra of $\mathbf{2} \mathbf{r} / \mathbf{2} \mathbf{r}^{\prime}$ before and after purification S3

3. ${ }^{1} \mathrm{H}$ and ${ }^{13} \mathrm{C}\left\{{ }^{1} \mathrm{H}\right\}$ NMR spectra $\mathrm{S} 4-\mathrm{S} 30$ 


\section{Experimental setup for the electrophotochemical reaction}
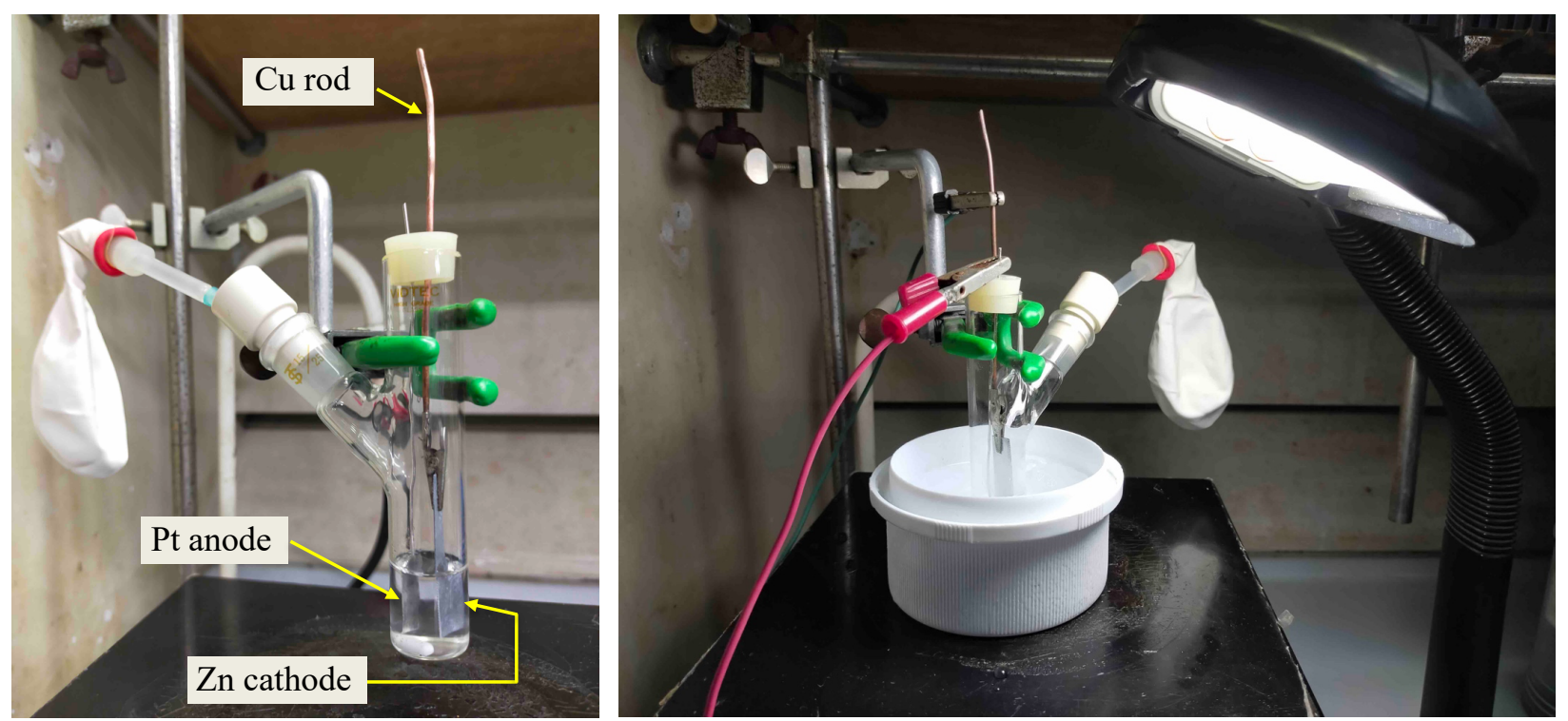

Figure S1. General reaction setup for a small-scale reaction.
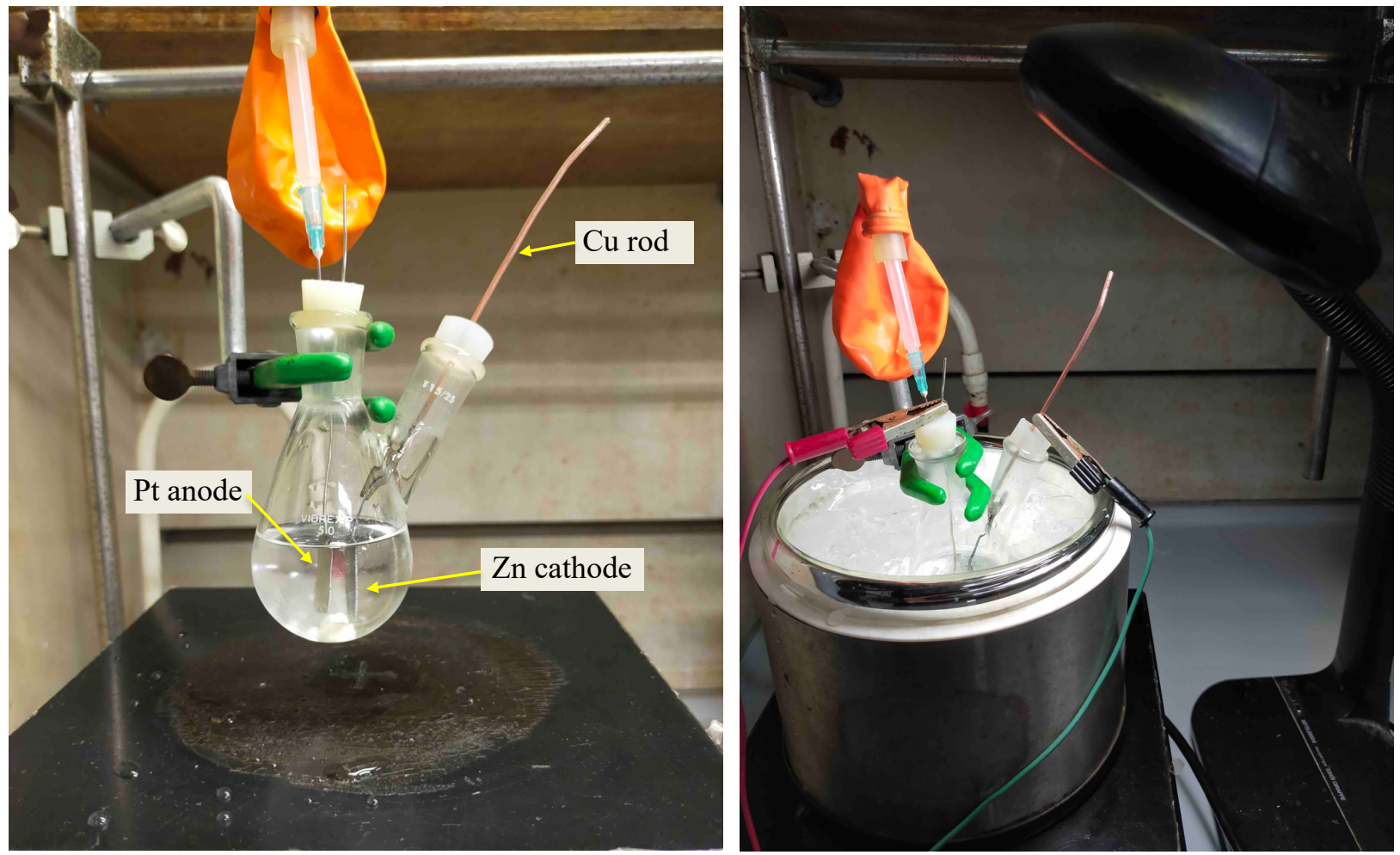

Figure S2. General reaction set up for a gram-scale reaction. 


\section{Partial ${ }^{1} \mathrm{H}$ and ${ }^{13} \mathrm{C}\left\{{ }^{1} \mathrm{H}\right\}$ NMR spectra of $2 \mathbf{r} / 2 \mathbf{r}^{\prime}$ before and after purification}

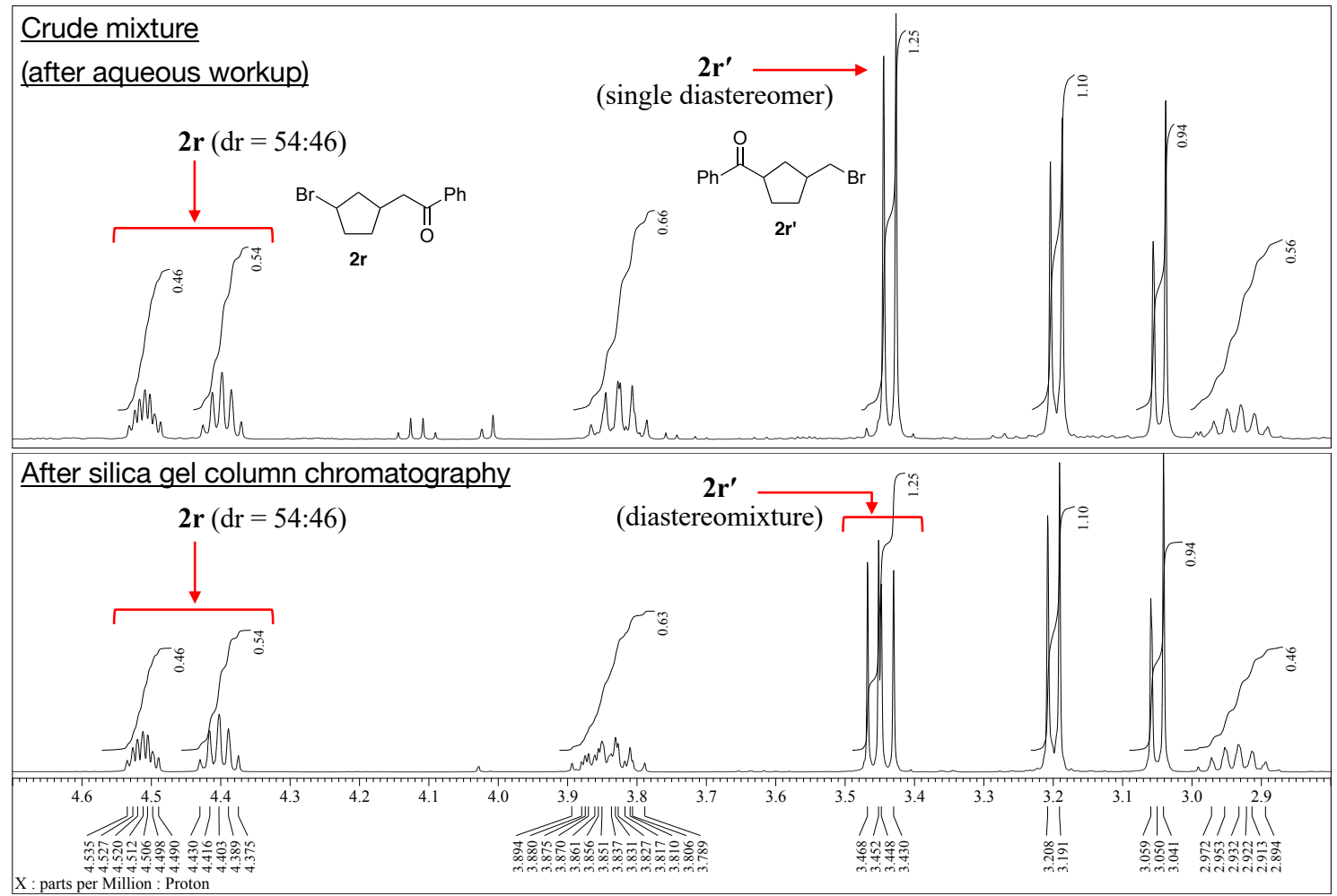

Figure S3. Expanded ${ }^{1} \mathrm{H}$ NMR spectra $\left(400 \mathrm{MHz}, \mathrm{CDCl}_{3}\right.$ ) of $\mathbf{2 r} / \mathbf{2} \mathbf{r}^{\prime}$ in the crude mixture (top) and after purification (bottom).

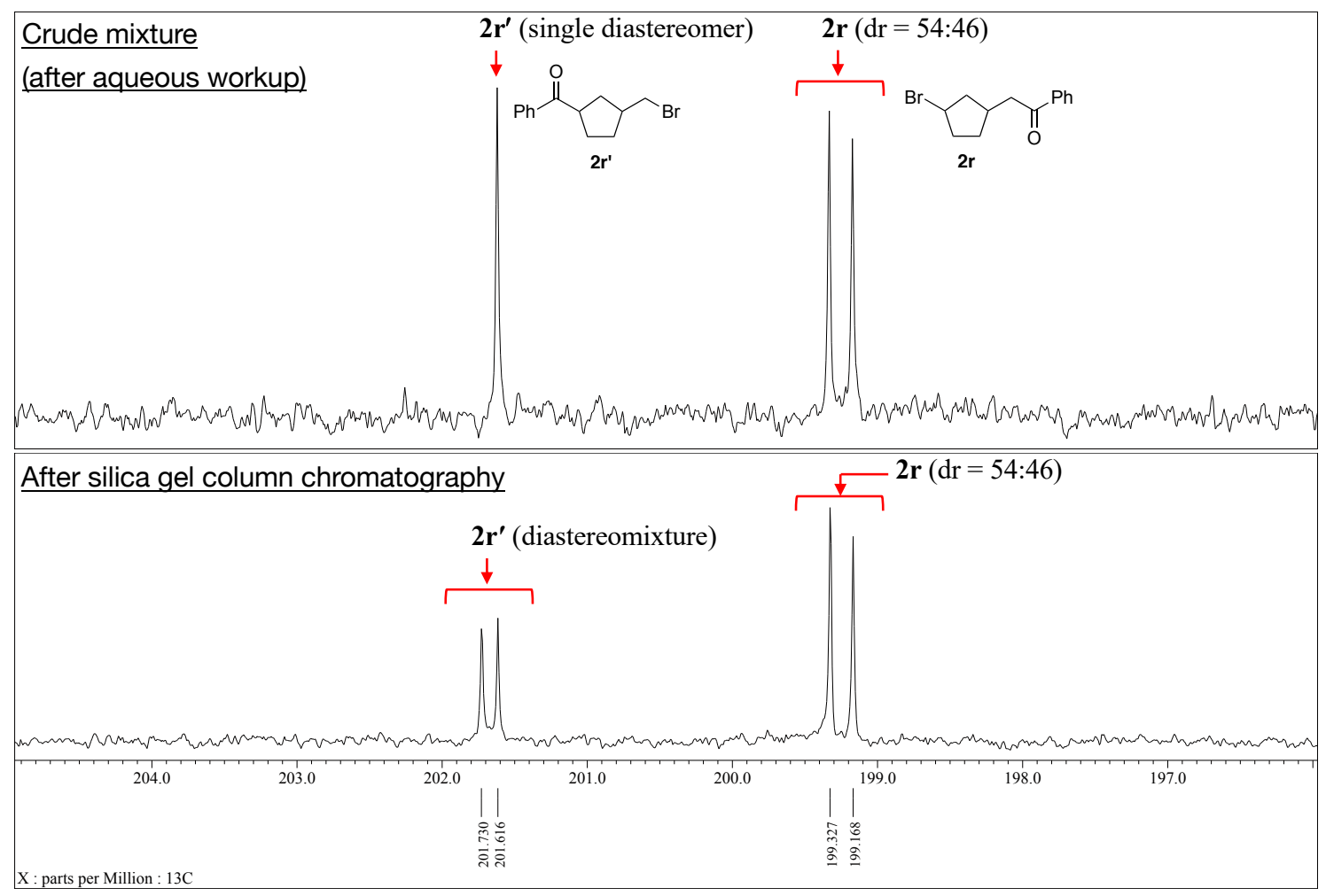

Figure S4. Expanded ${ }^{13} \mathrm{C}\left\{{ }^{1} \mathrm{H}\right\}$ NMR spectra $\left(500 \mathrm{MHz}, \mathrm{CDCl}_{3}\right)$ of $\mathbf{2} \mathbf{r} / \mathbf{2} \mathbf{r}^{\prime}$ in the crude mixture (top) and after purification (bottom). 


\section{3. ${ }^{1} \mathrm{H}$ and ${ }^{13} \mathrm{C}\left\{{ }^{1} \mathrm{H}\right\}$ NMR spectra}
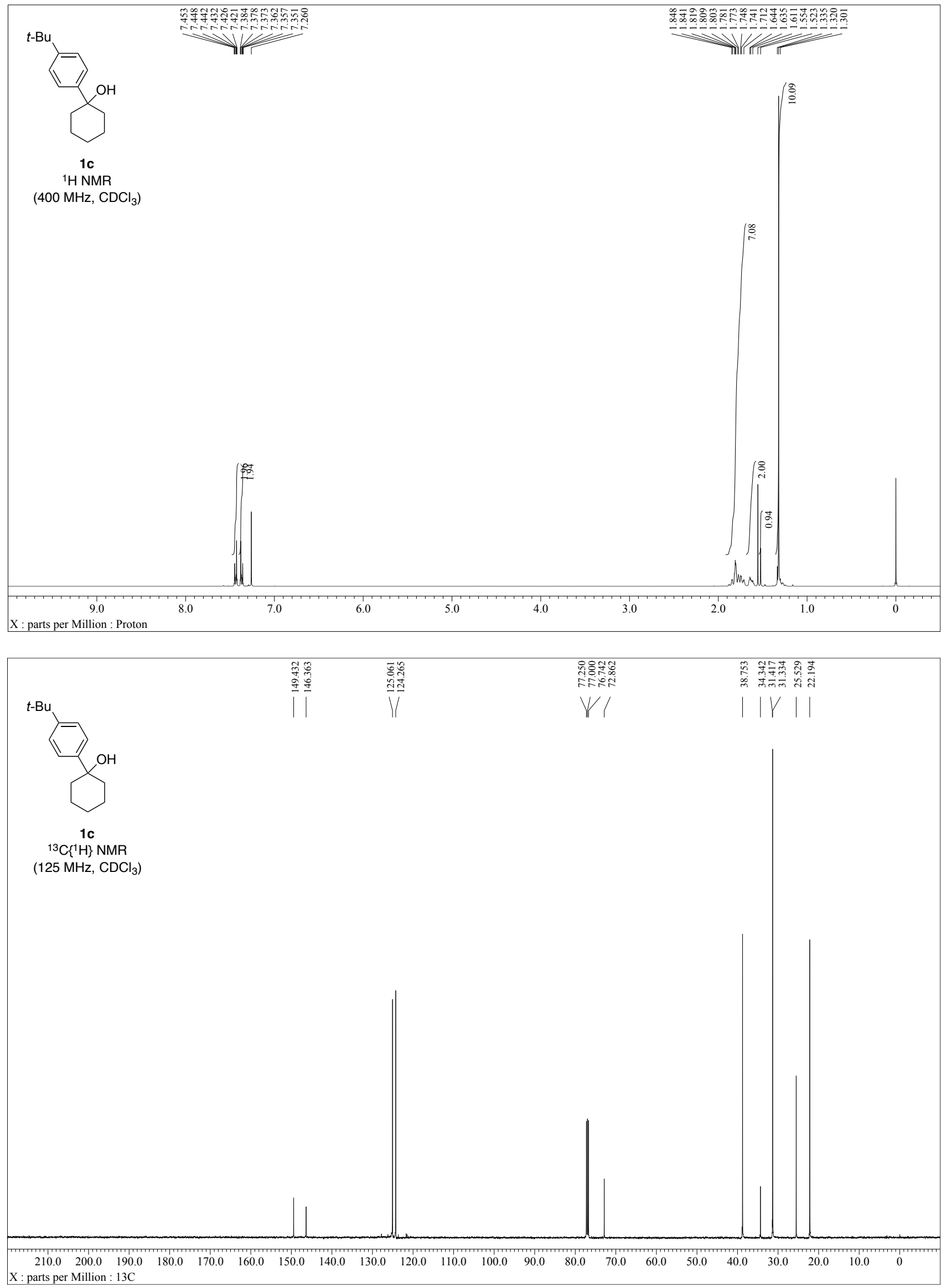

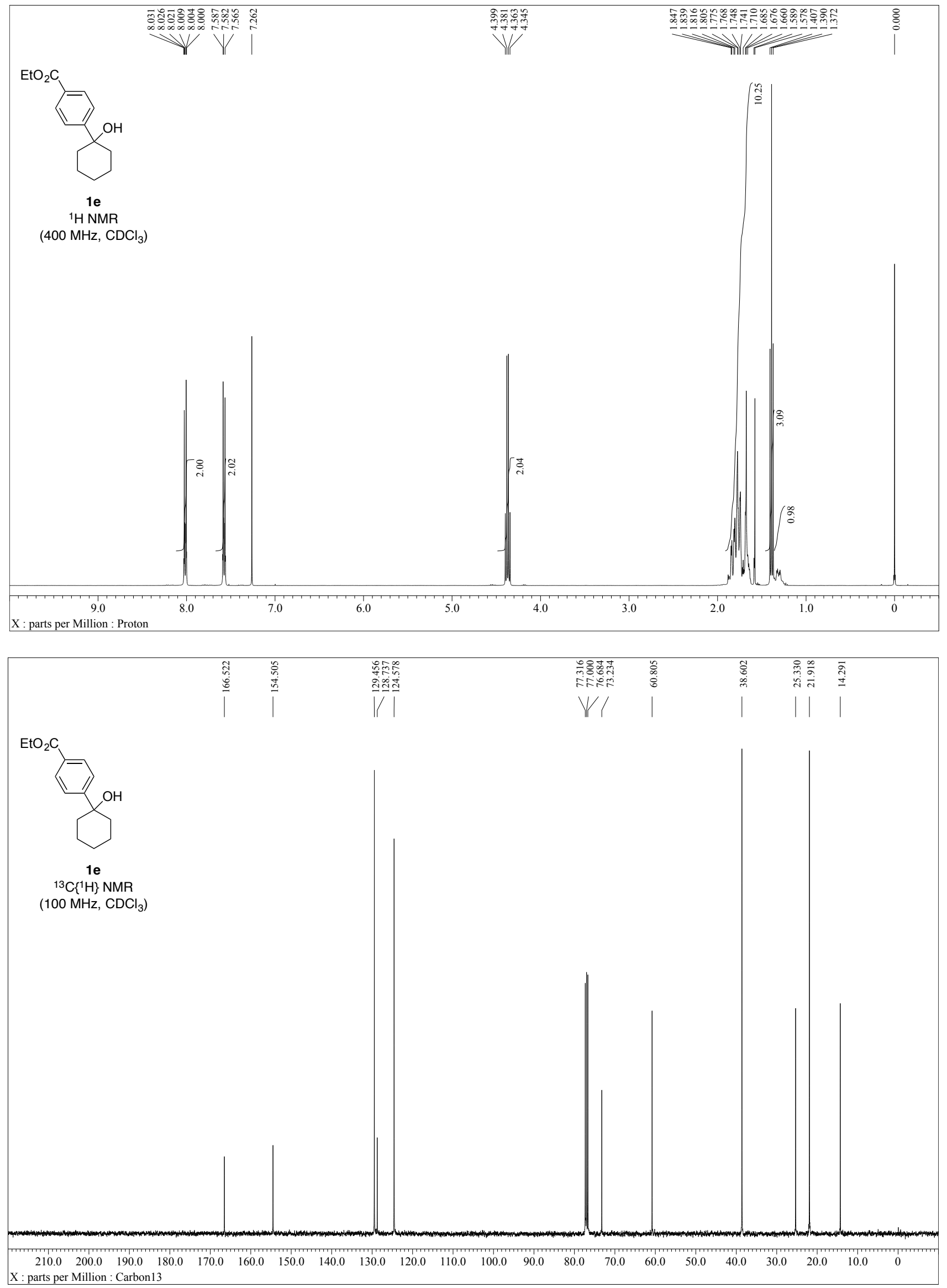

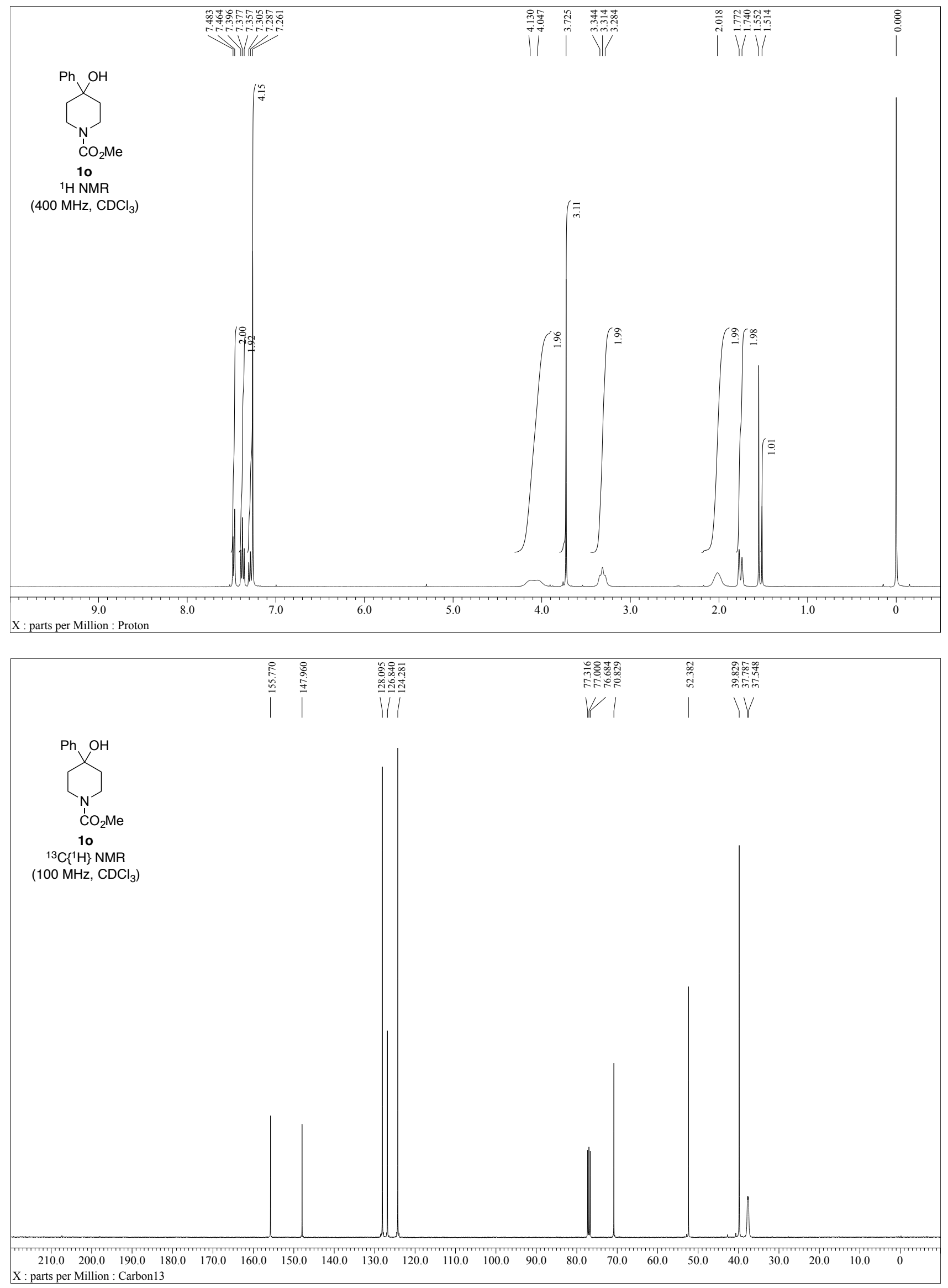

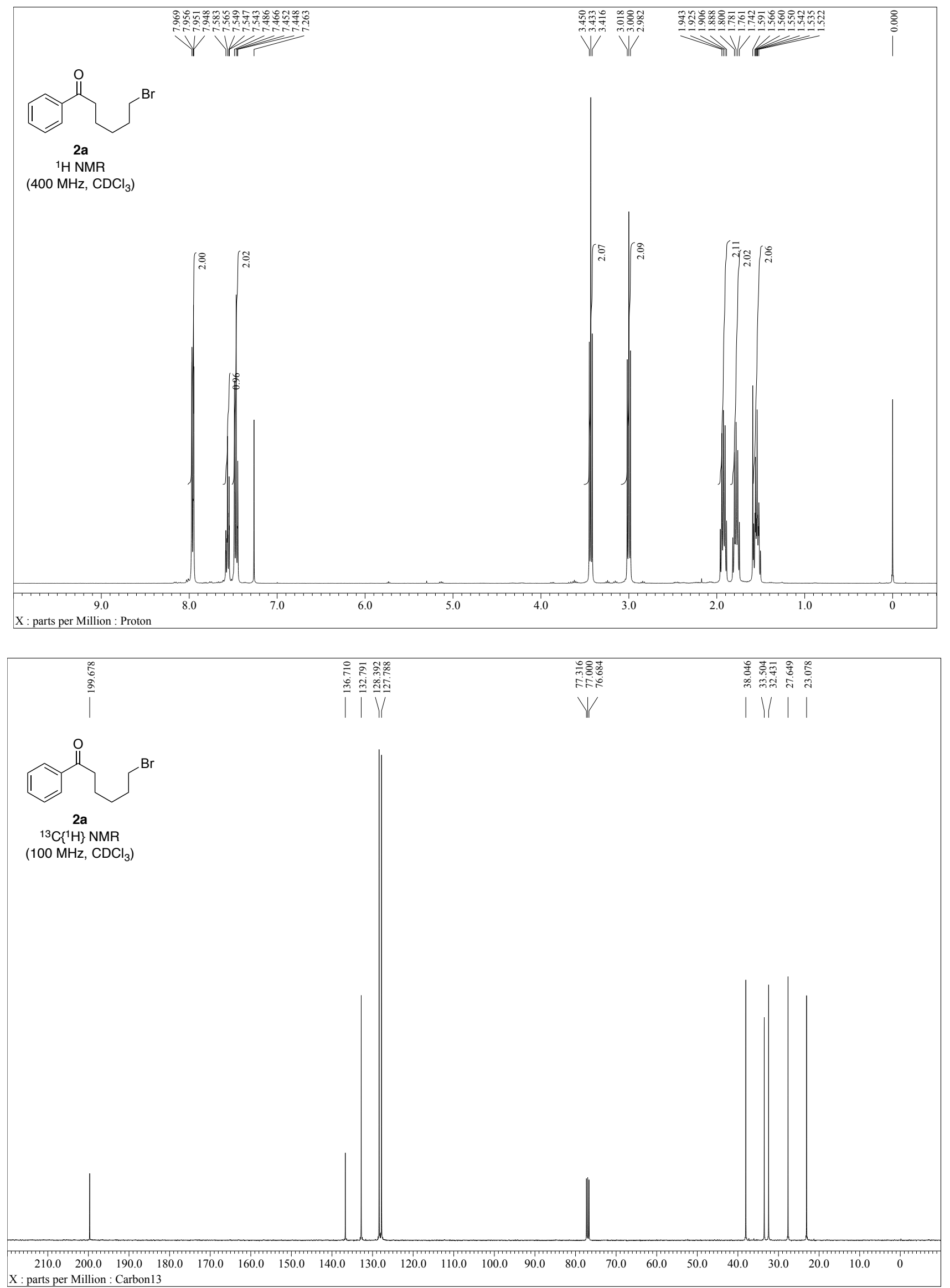

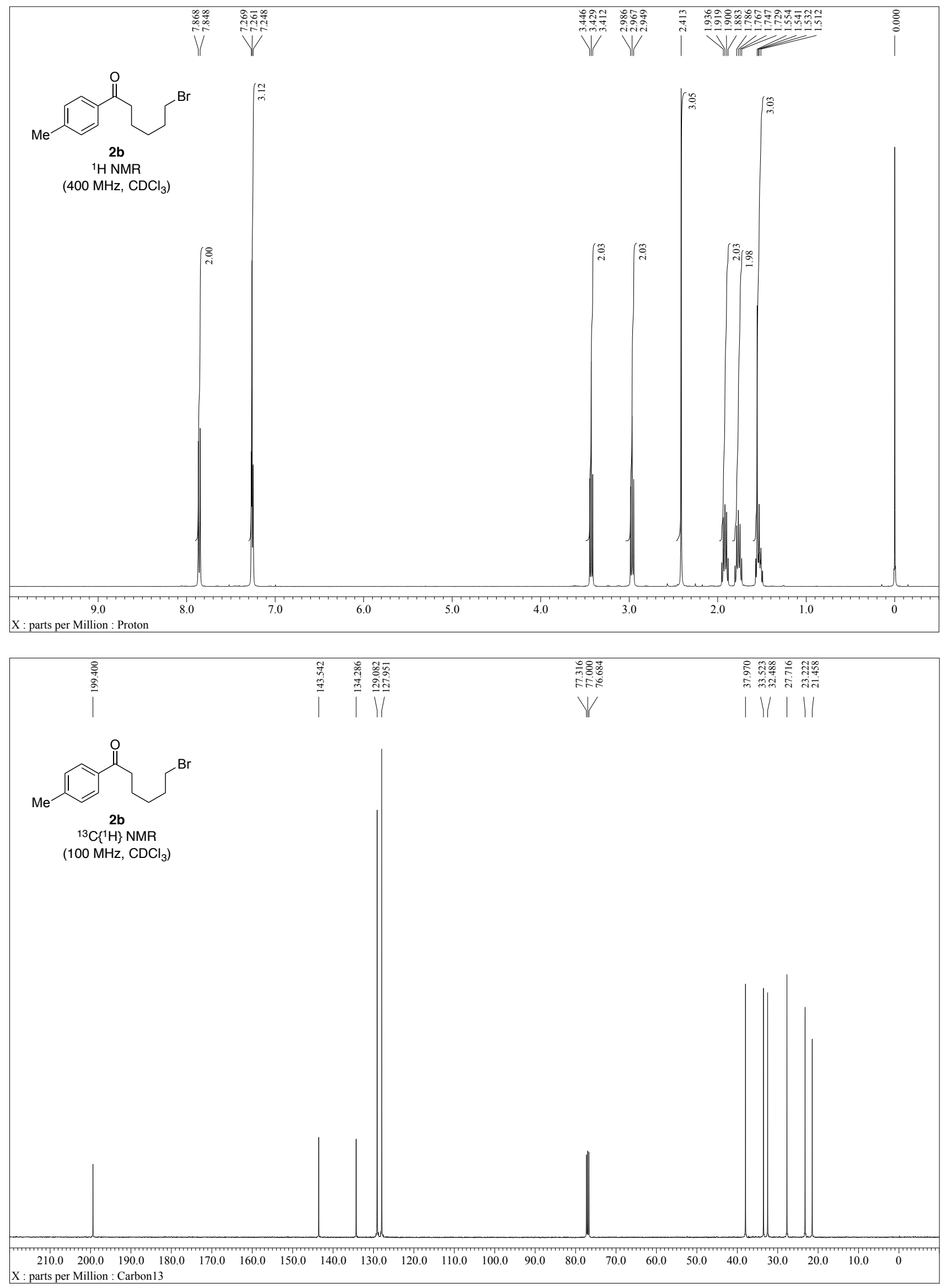

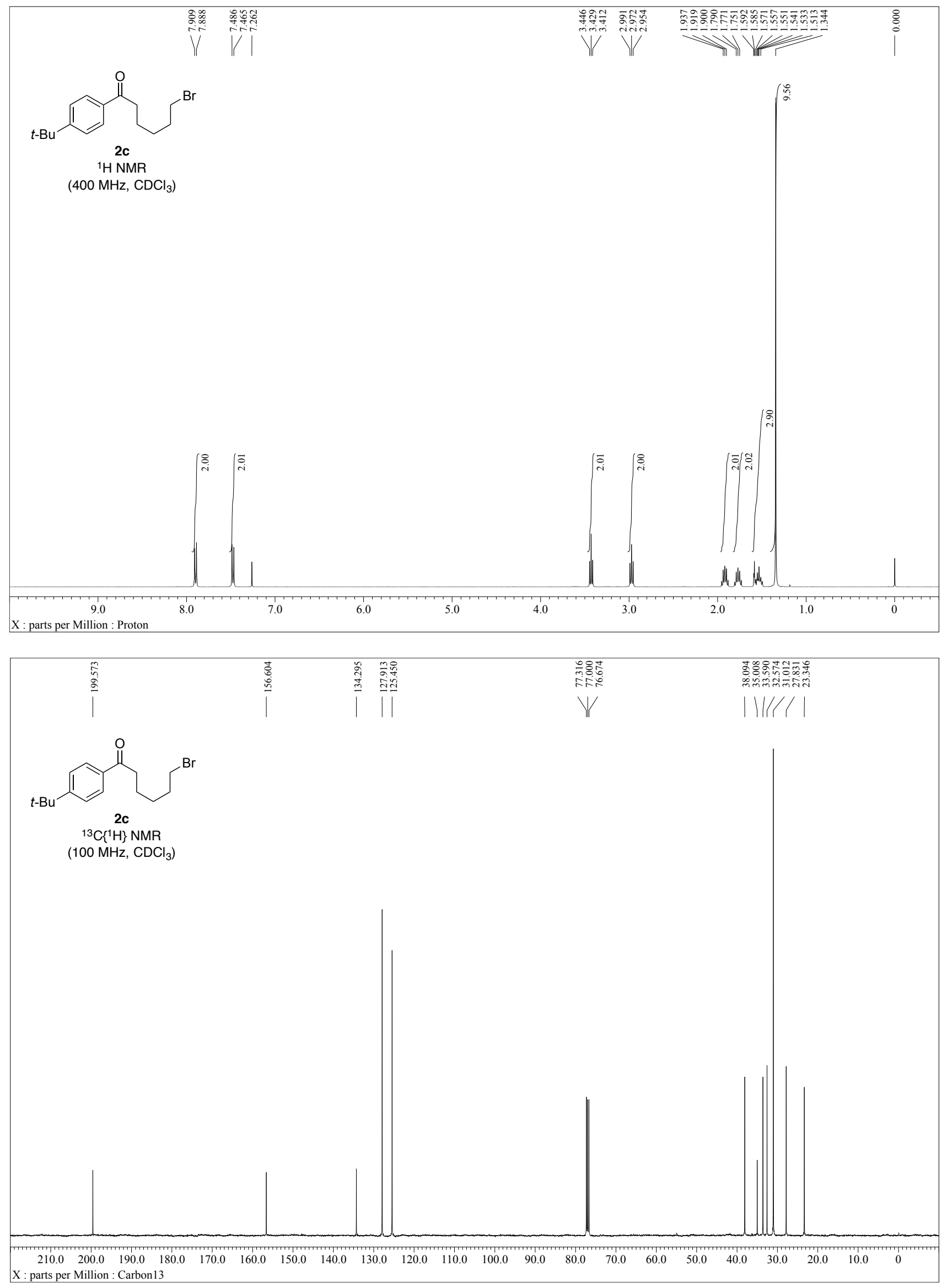

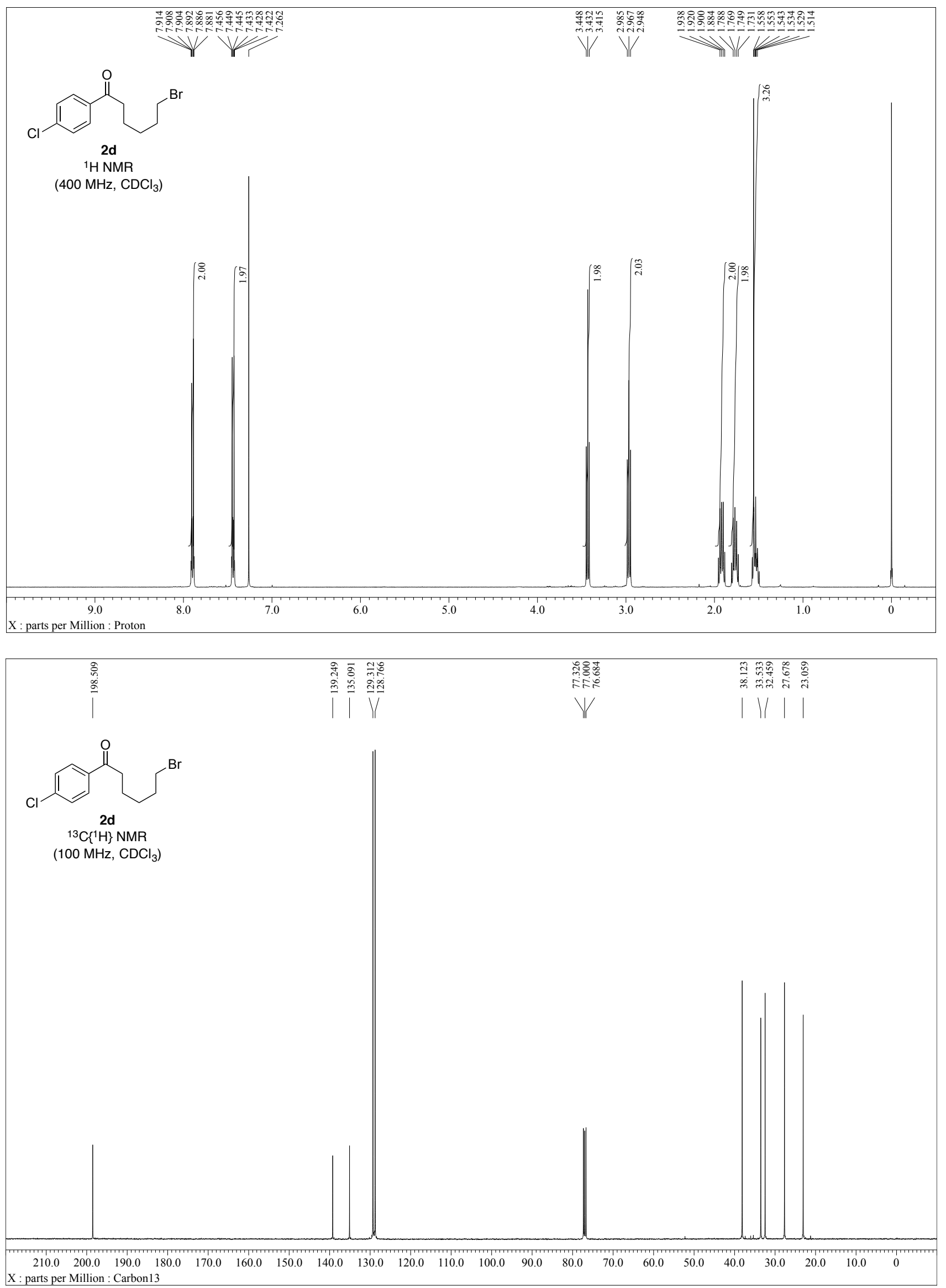

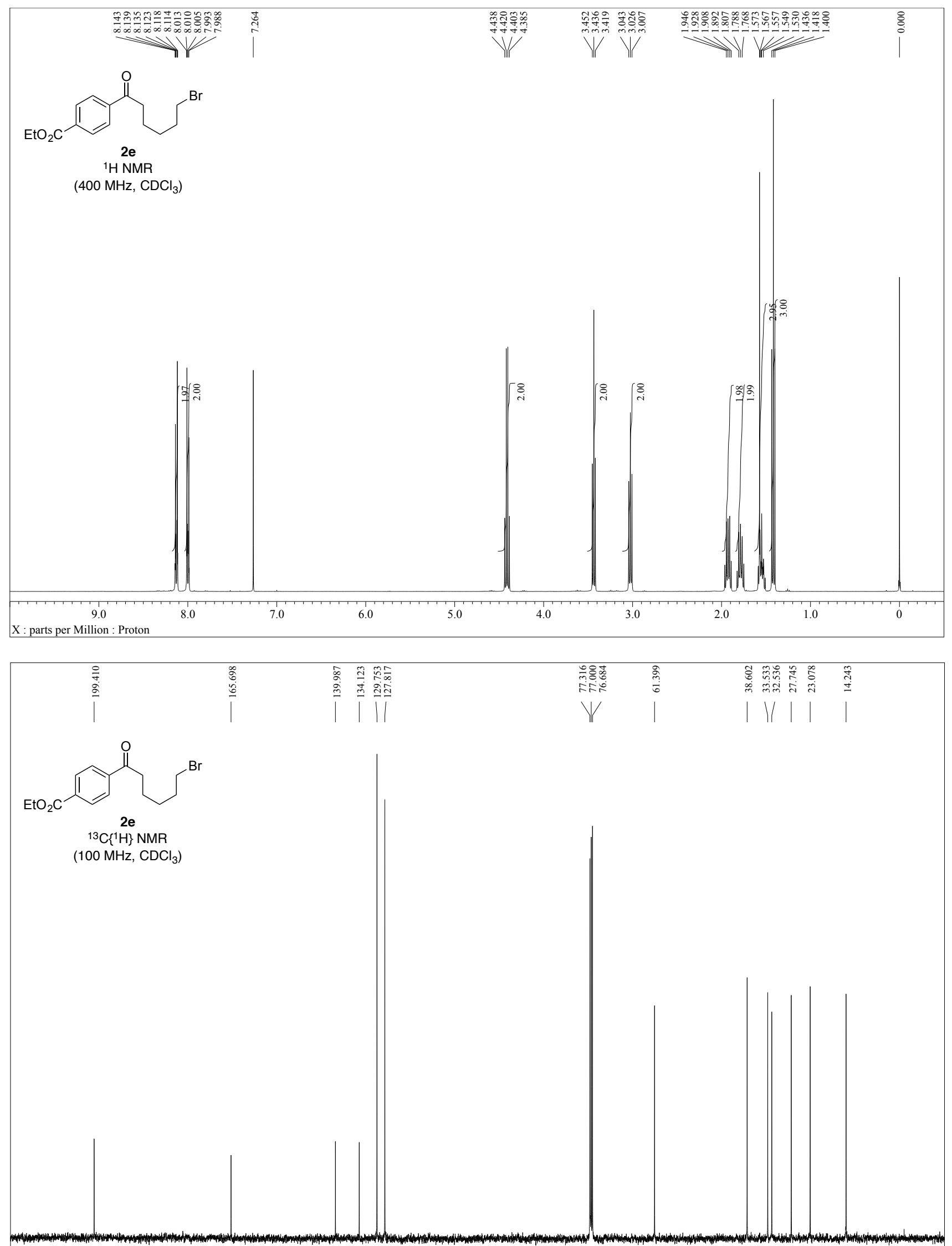

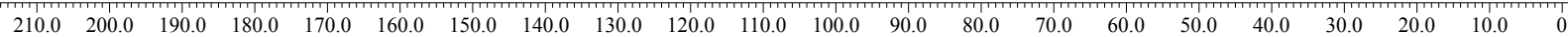
$\mathrm{X}$ : parts per Million : Carbon13 


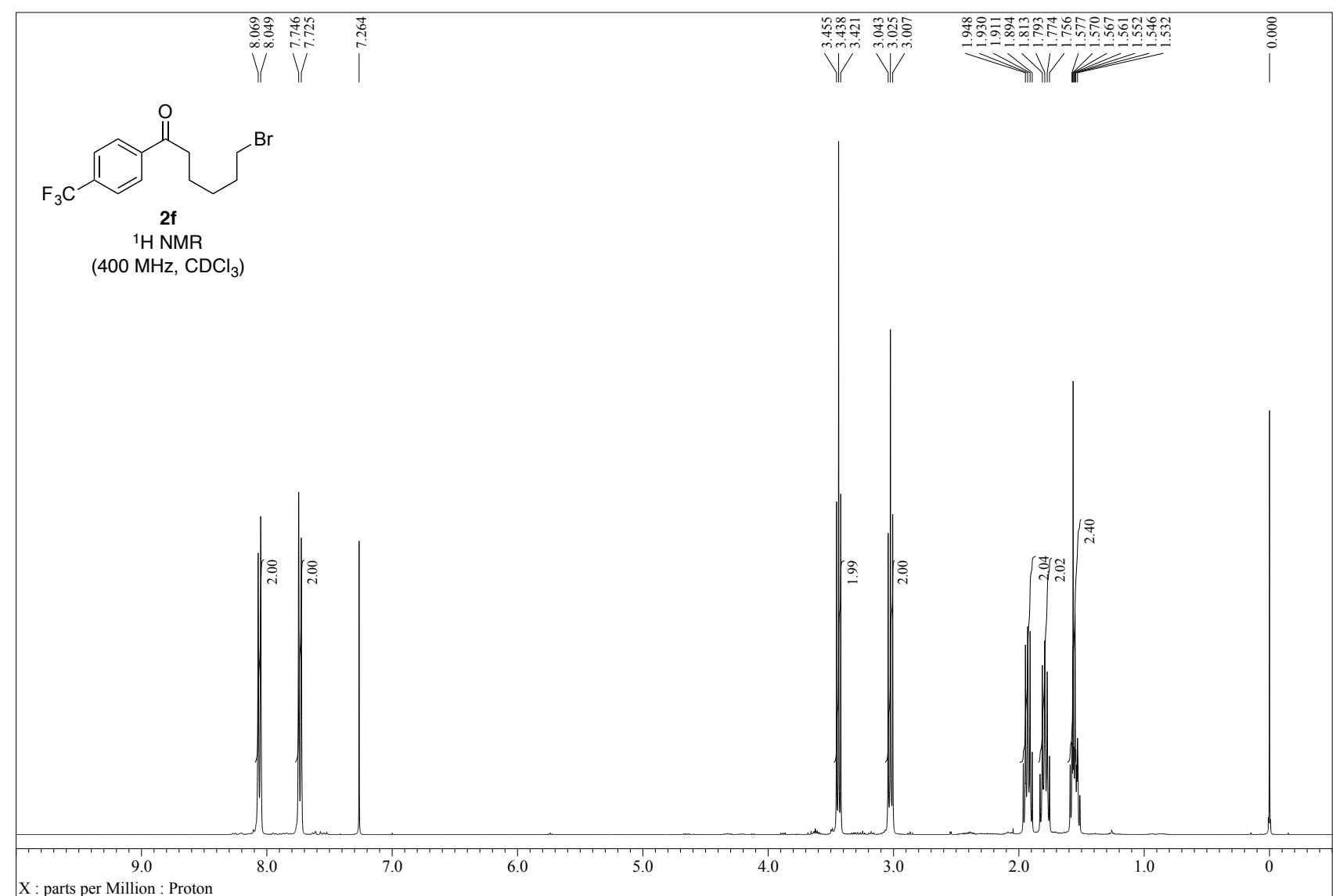

$\mathrm{X}$ : parts per Million : Proton

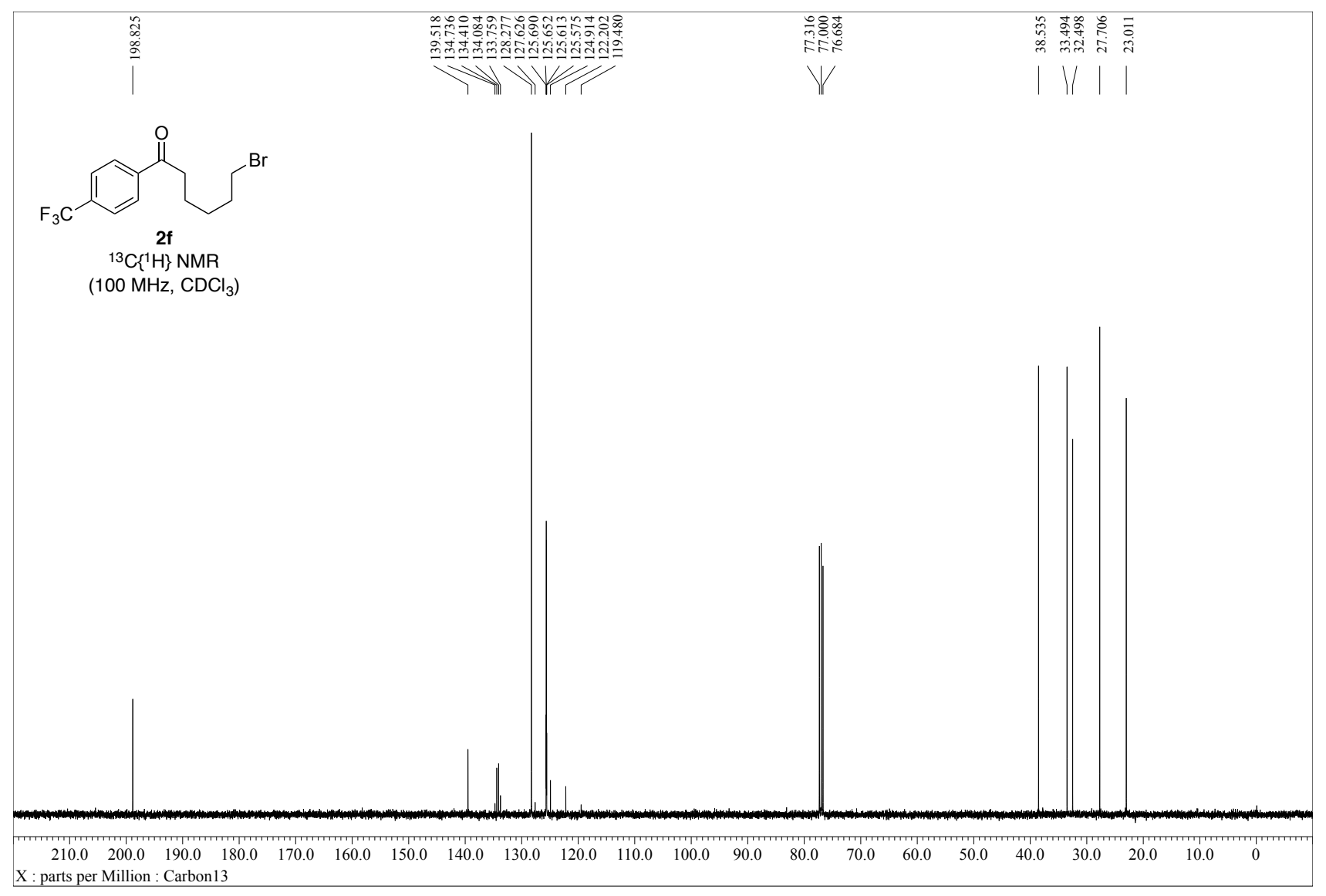



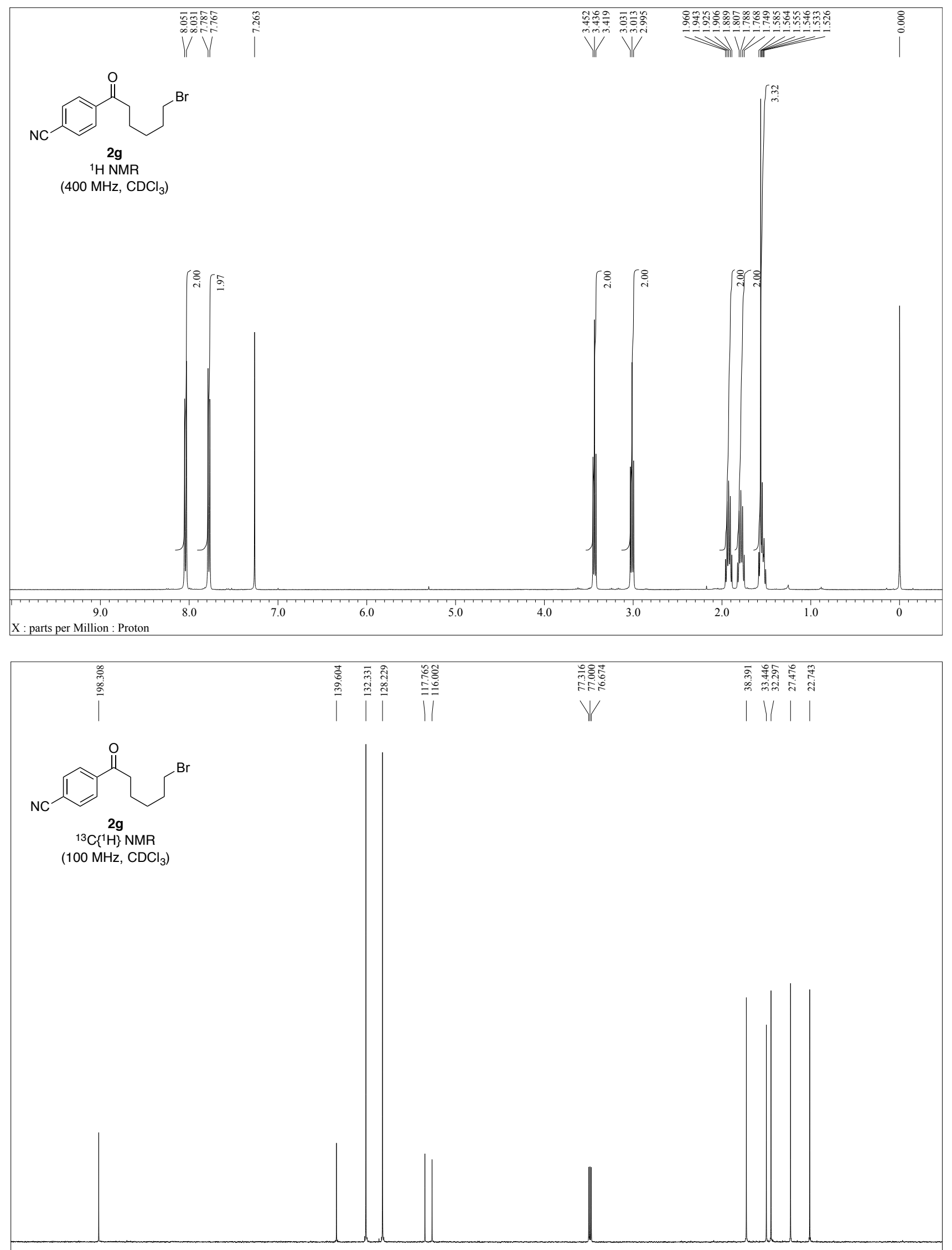

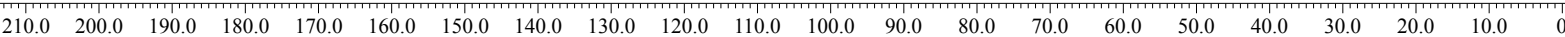
$\mathrm{X}$ : parts per Million : Carbon13 

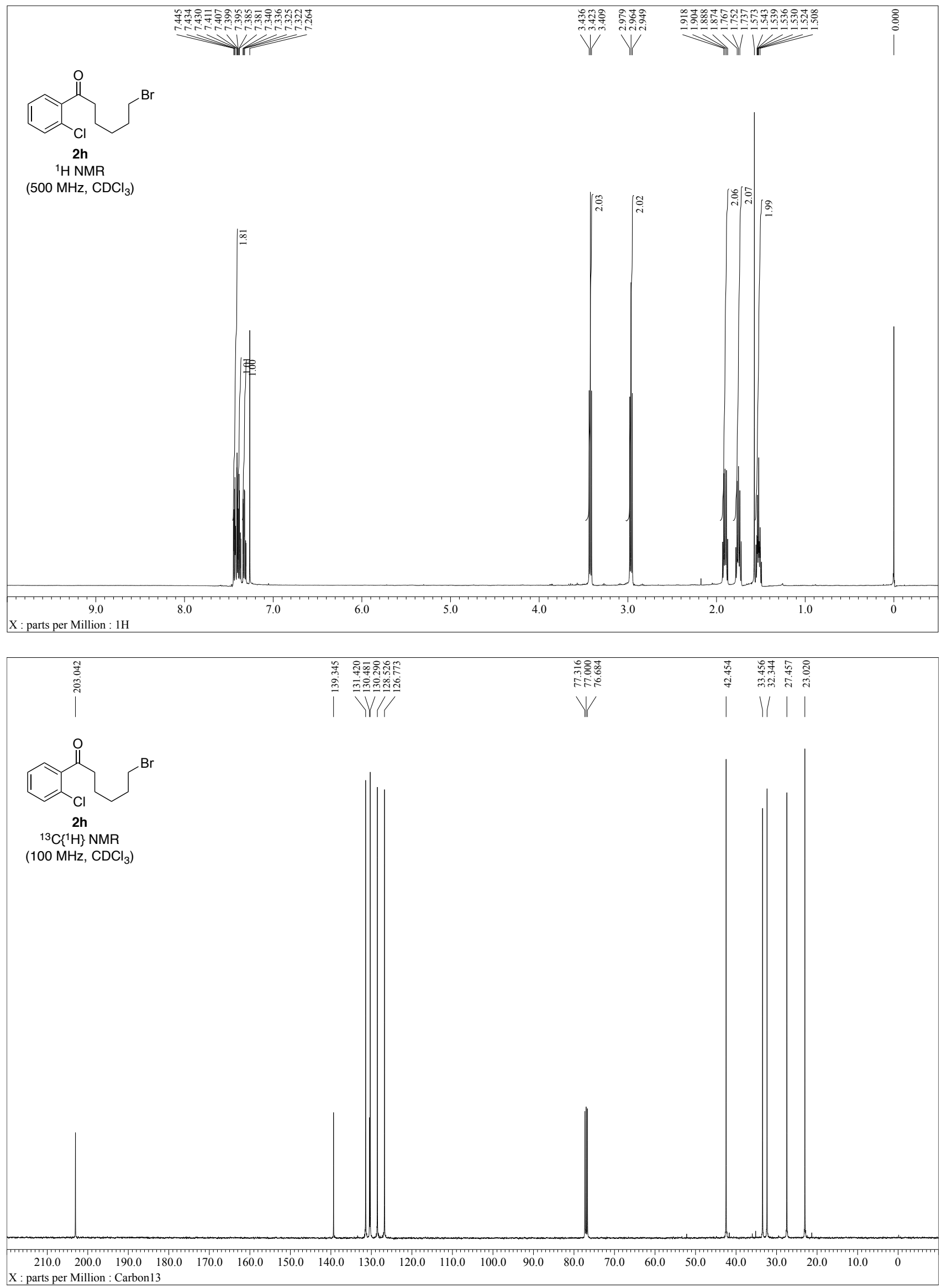

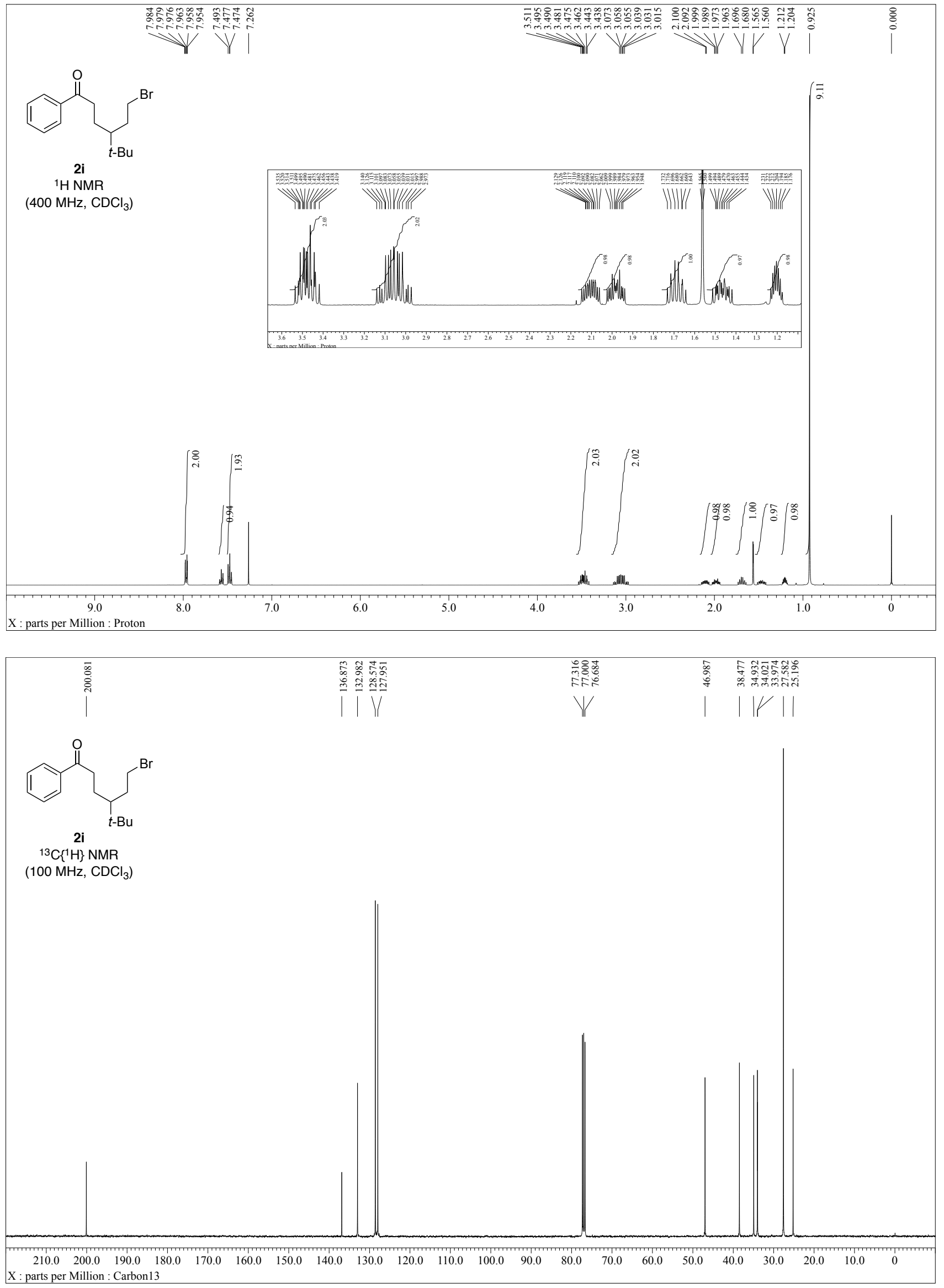

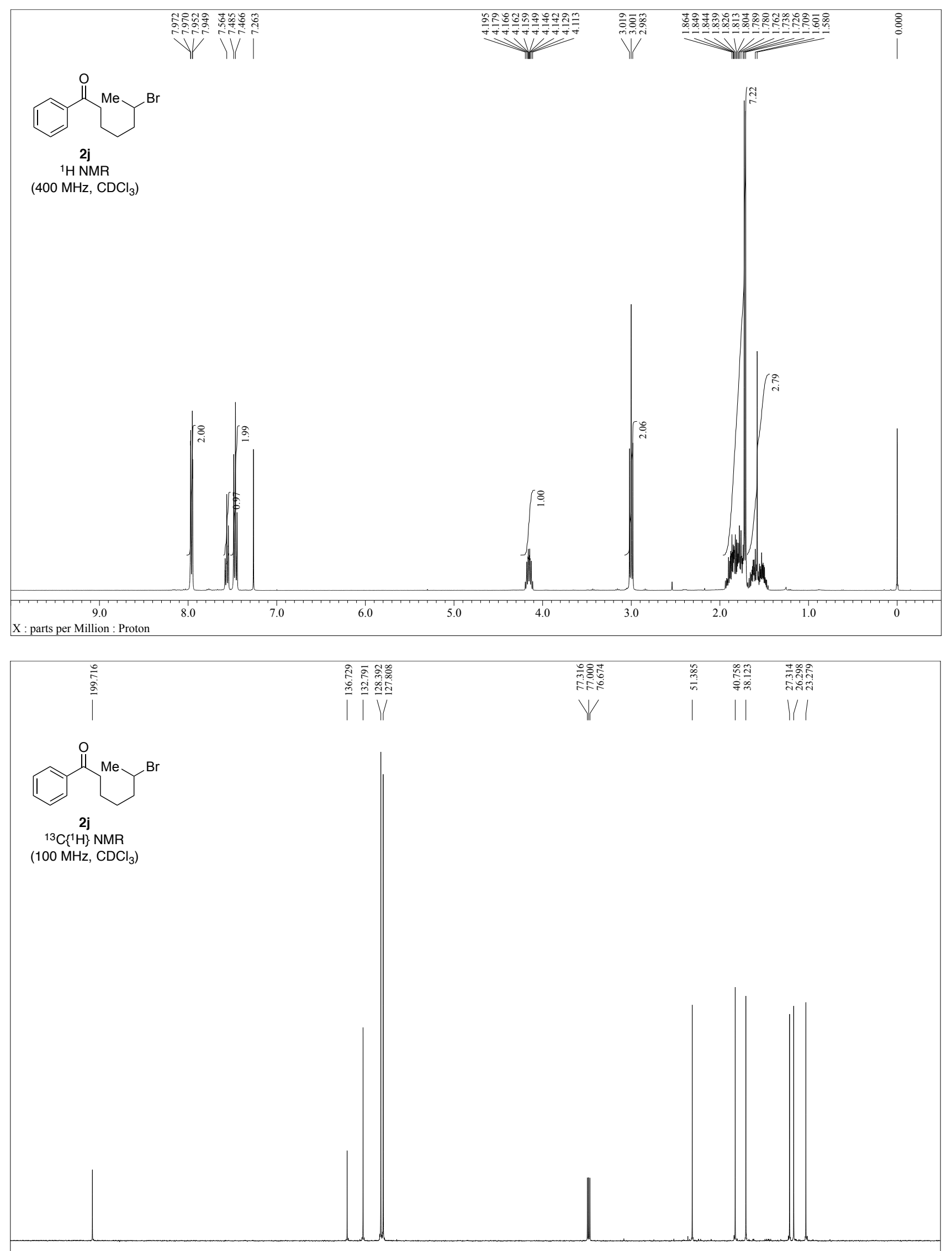

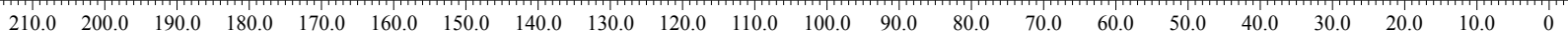
$\mathrm{X}$ : parts per Million : Carbon13 

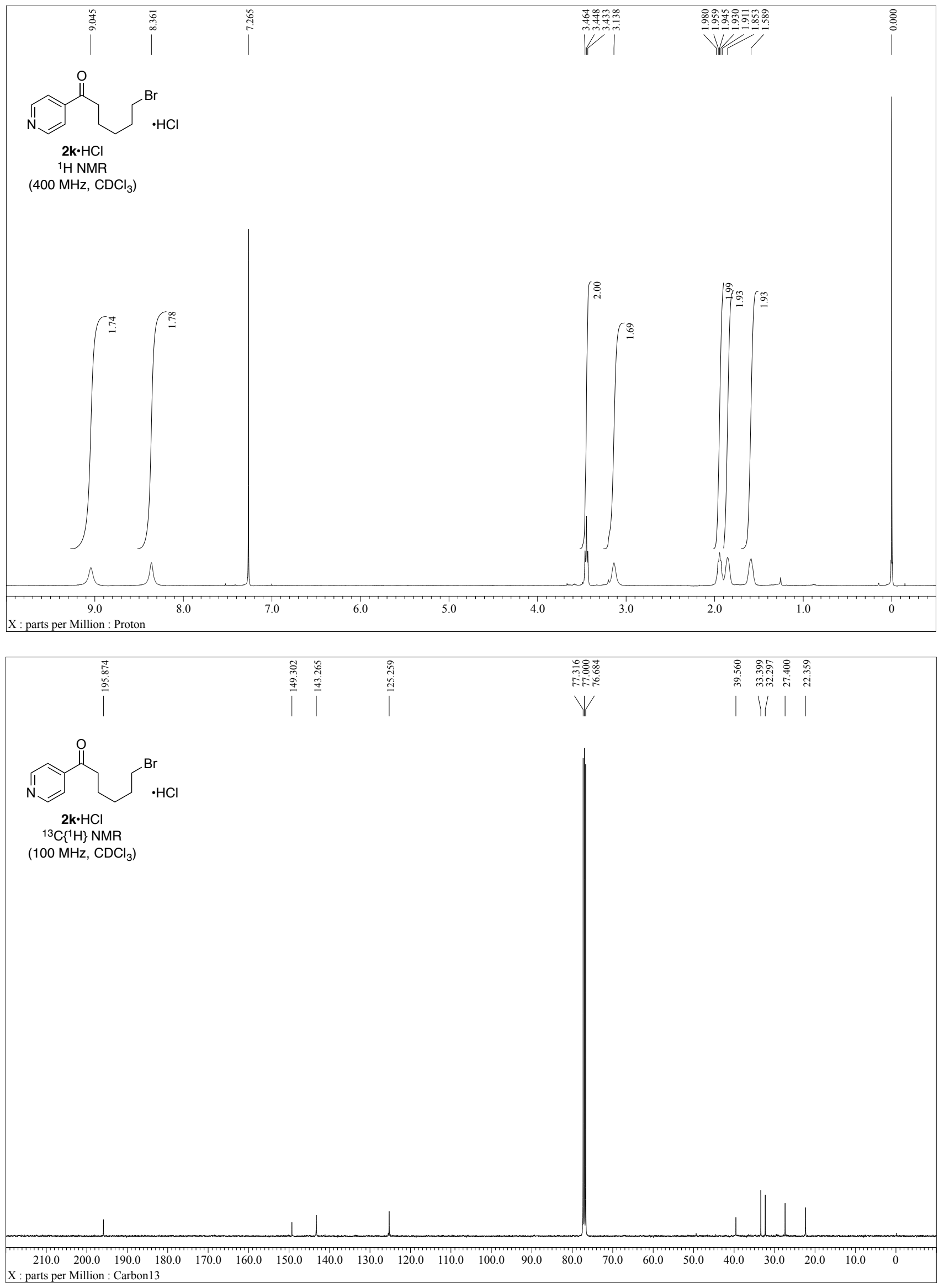

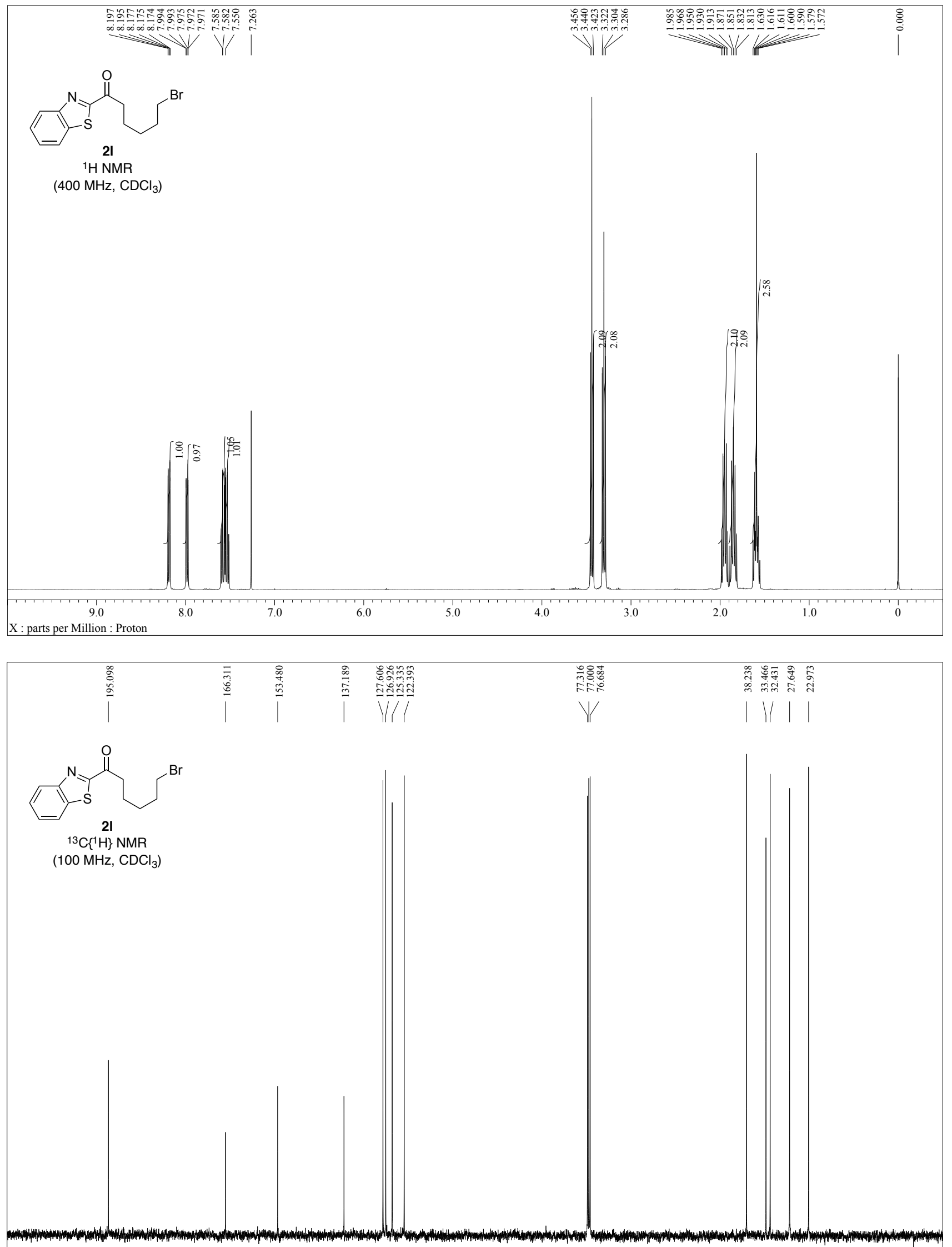

\begin{tabular}{llllllllllllllll}
\hline & 0.0
\end{tabular} $\mathrm{X}$ : parts per Million : Carbon 13 

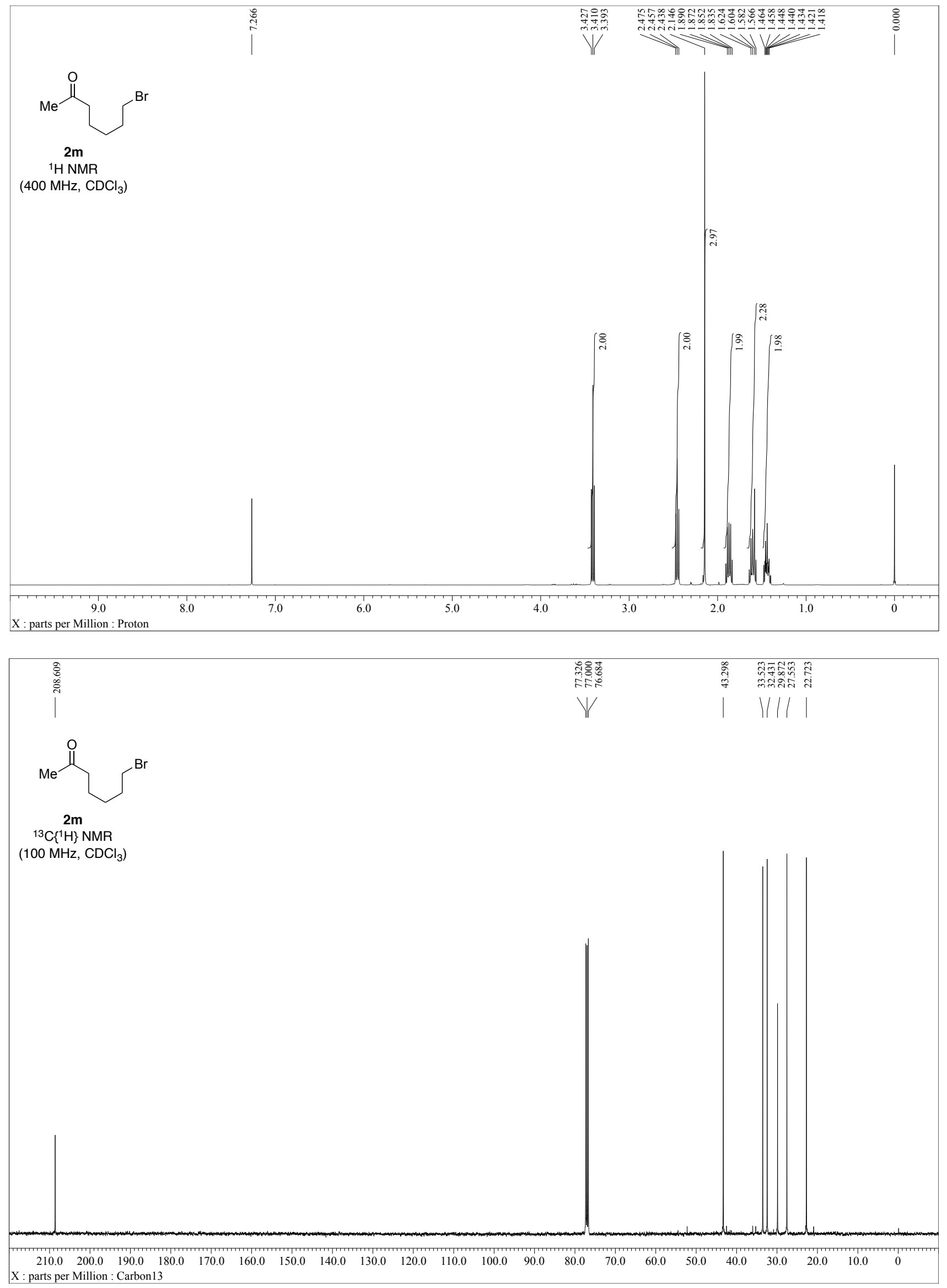


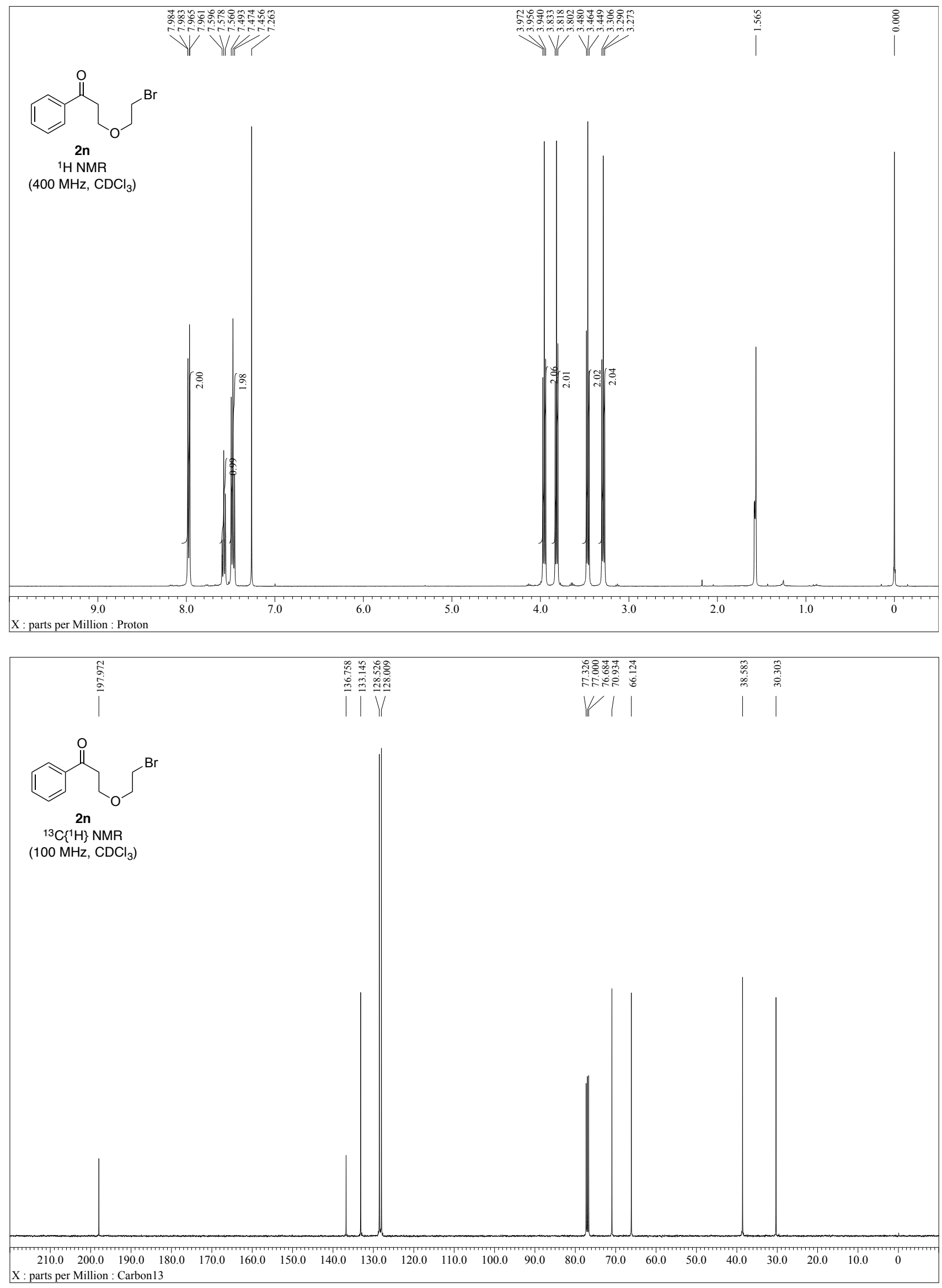



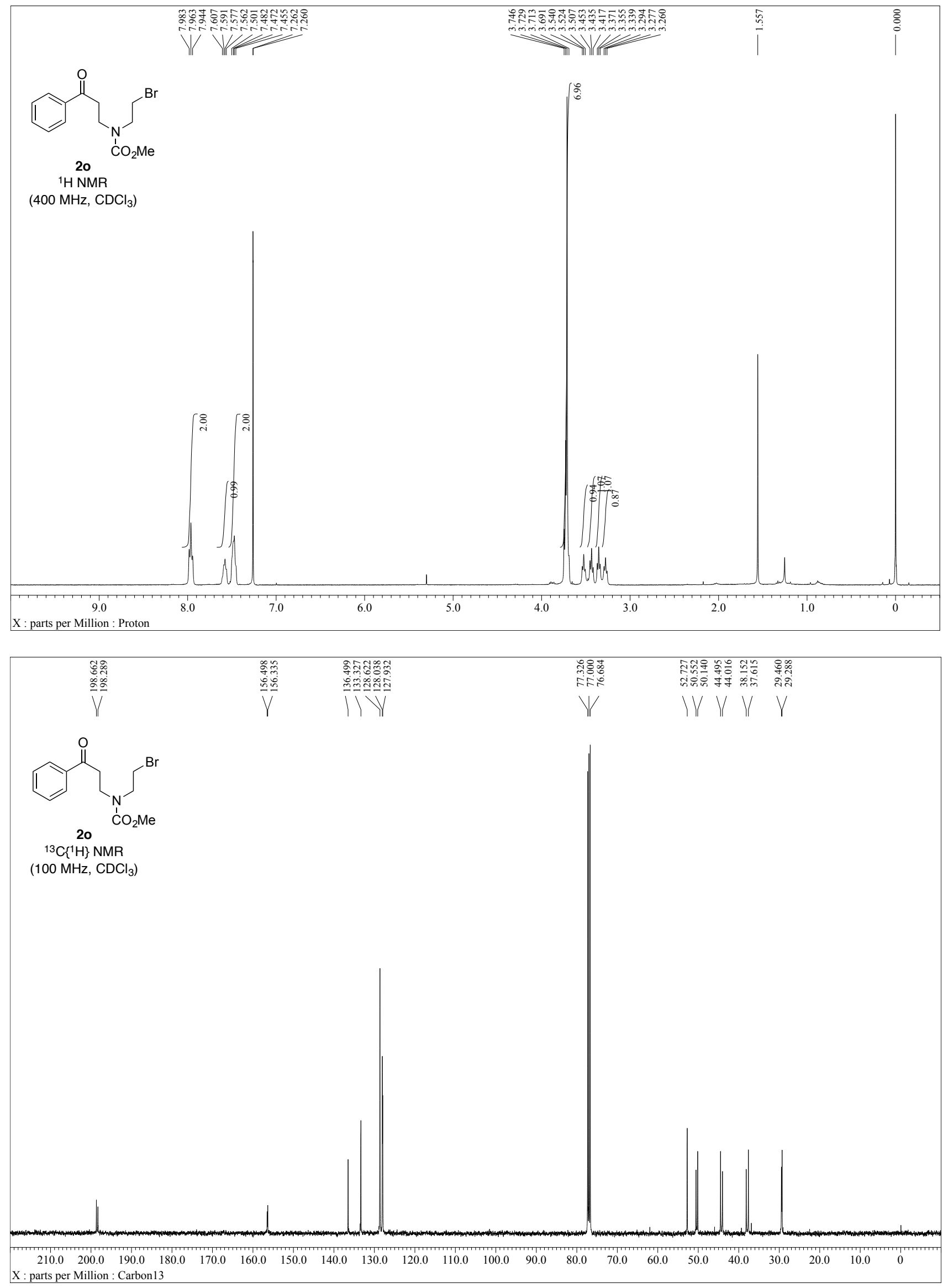


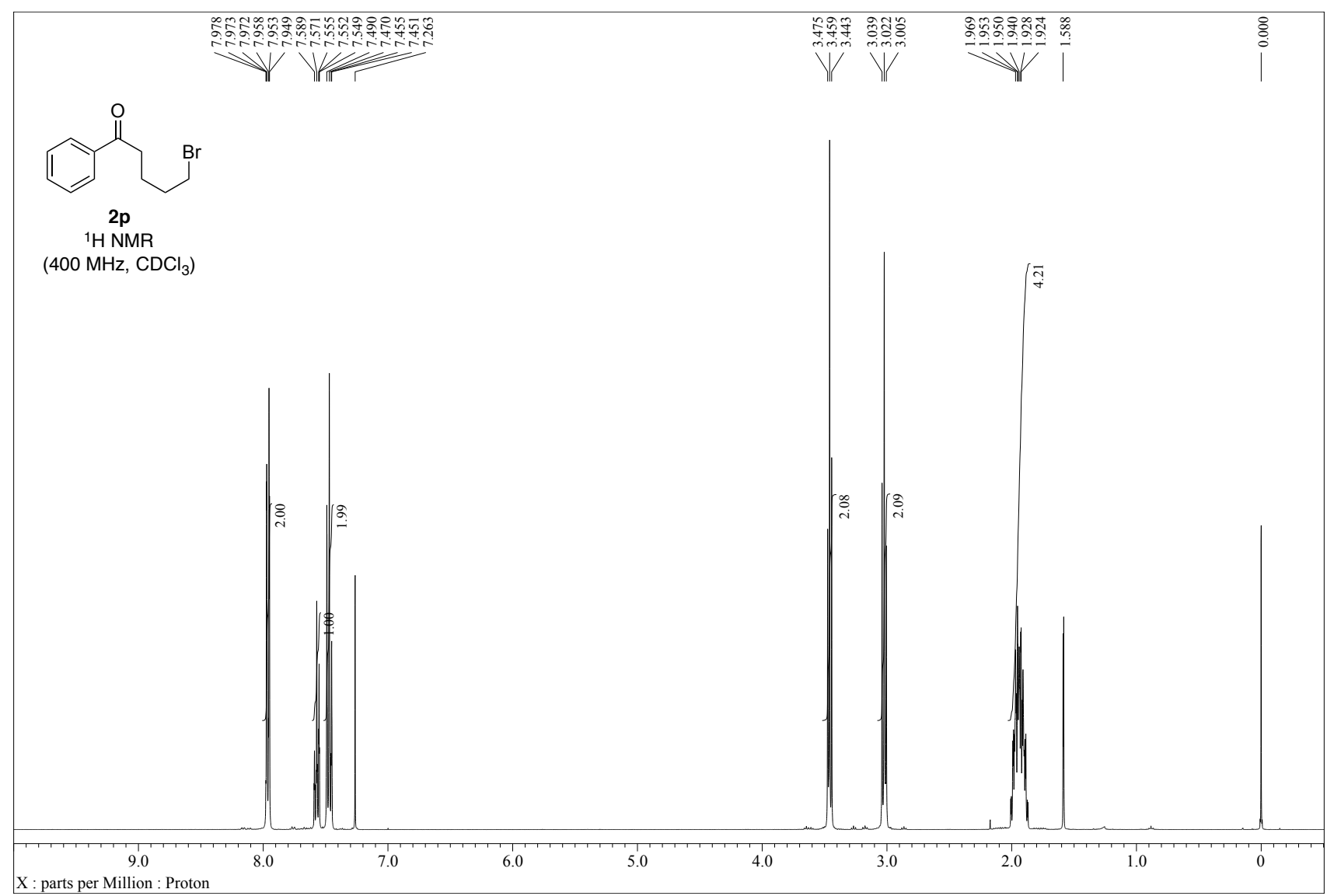

$\mathrm{X}$ : parts per Million : Proton

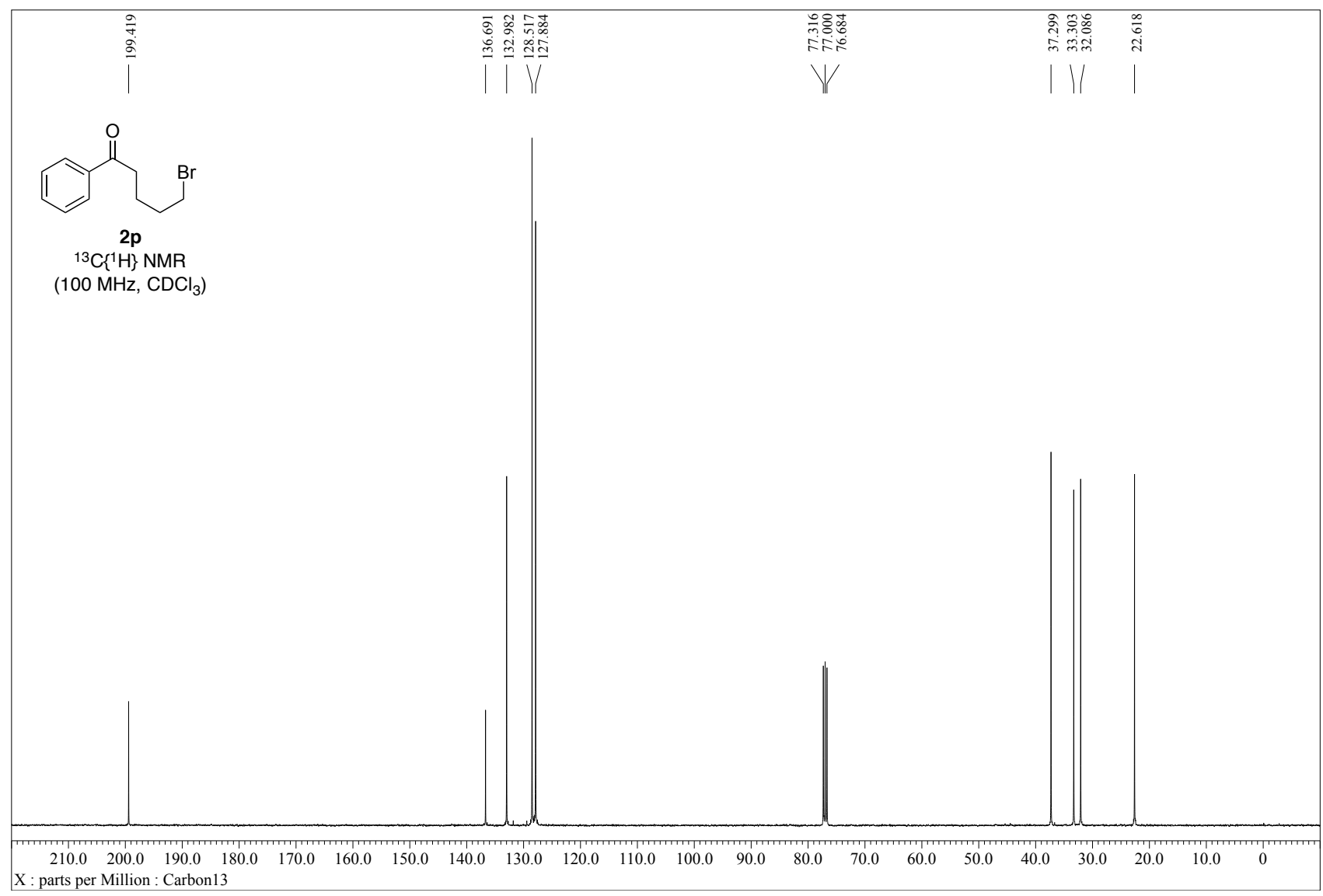




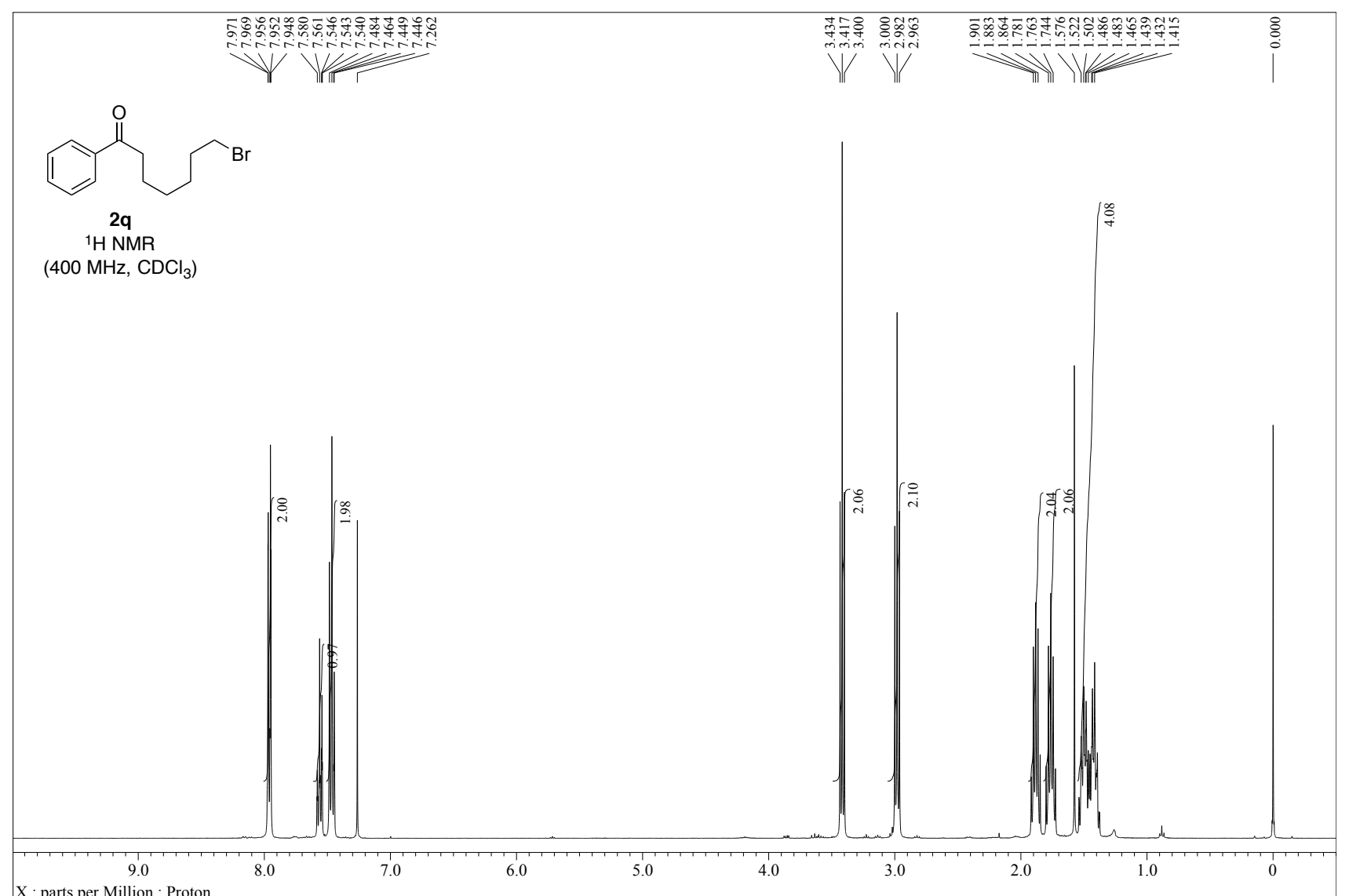

$\mathrm{X}$ : parts per Million : Proton

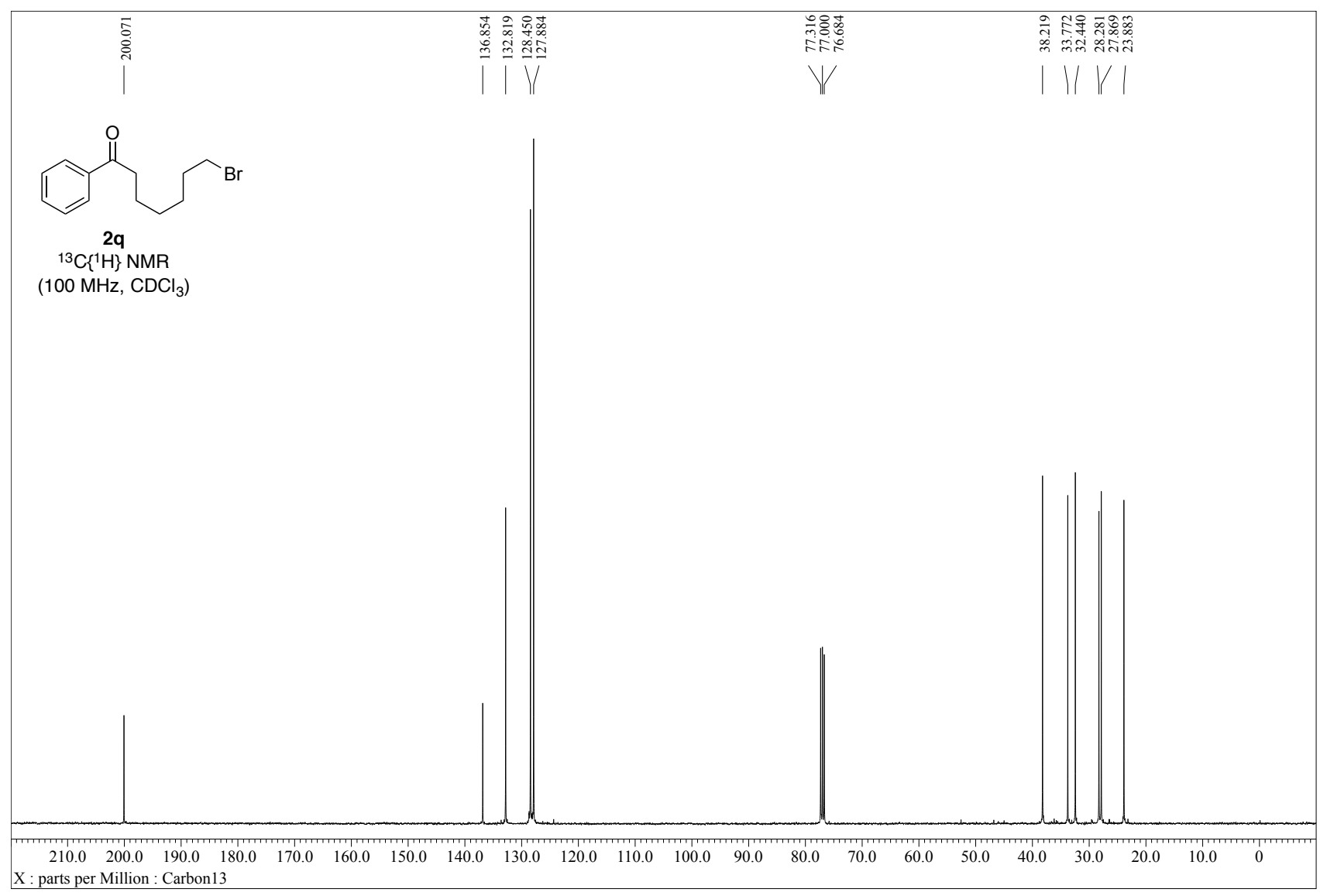



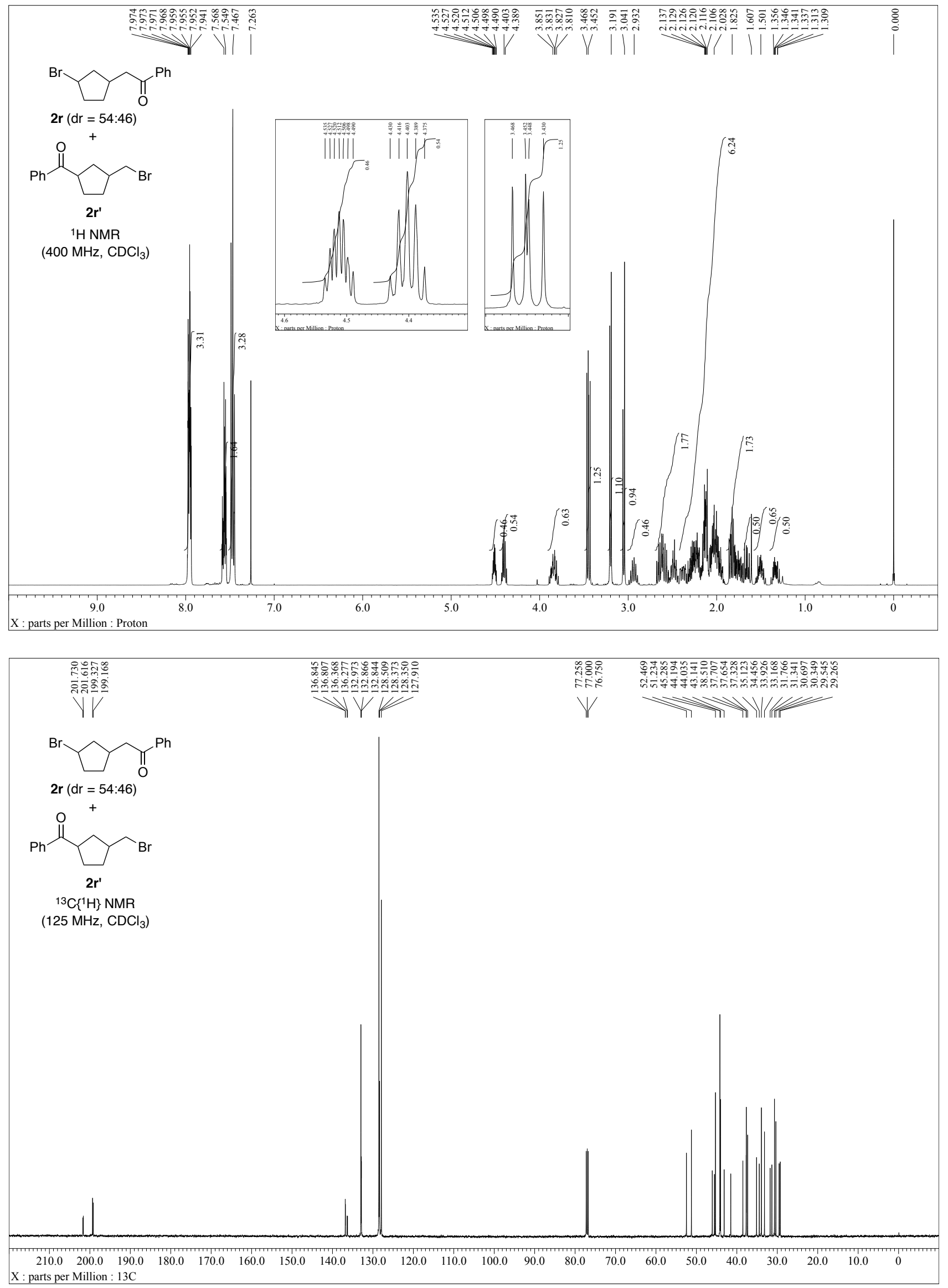


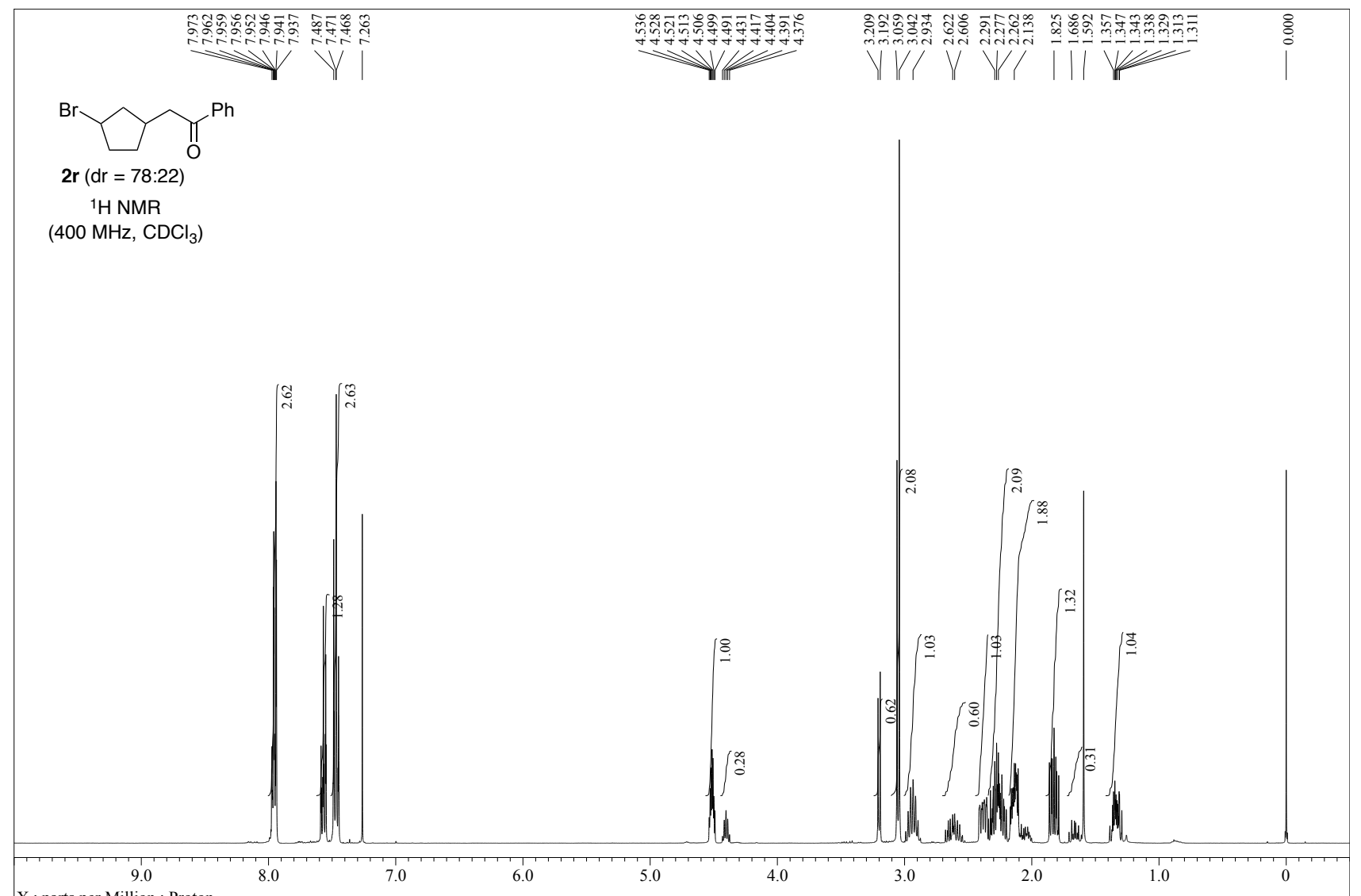

$\mathrm{X}$ : parts per Million : Proton

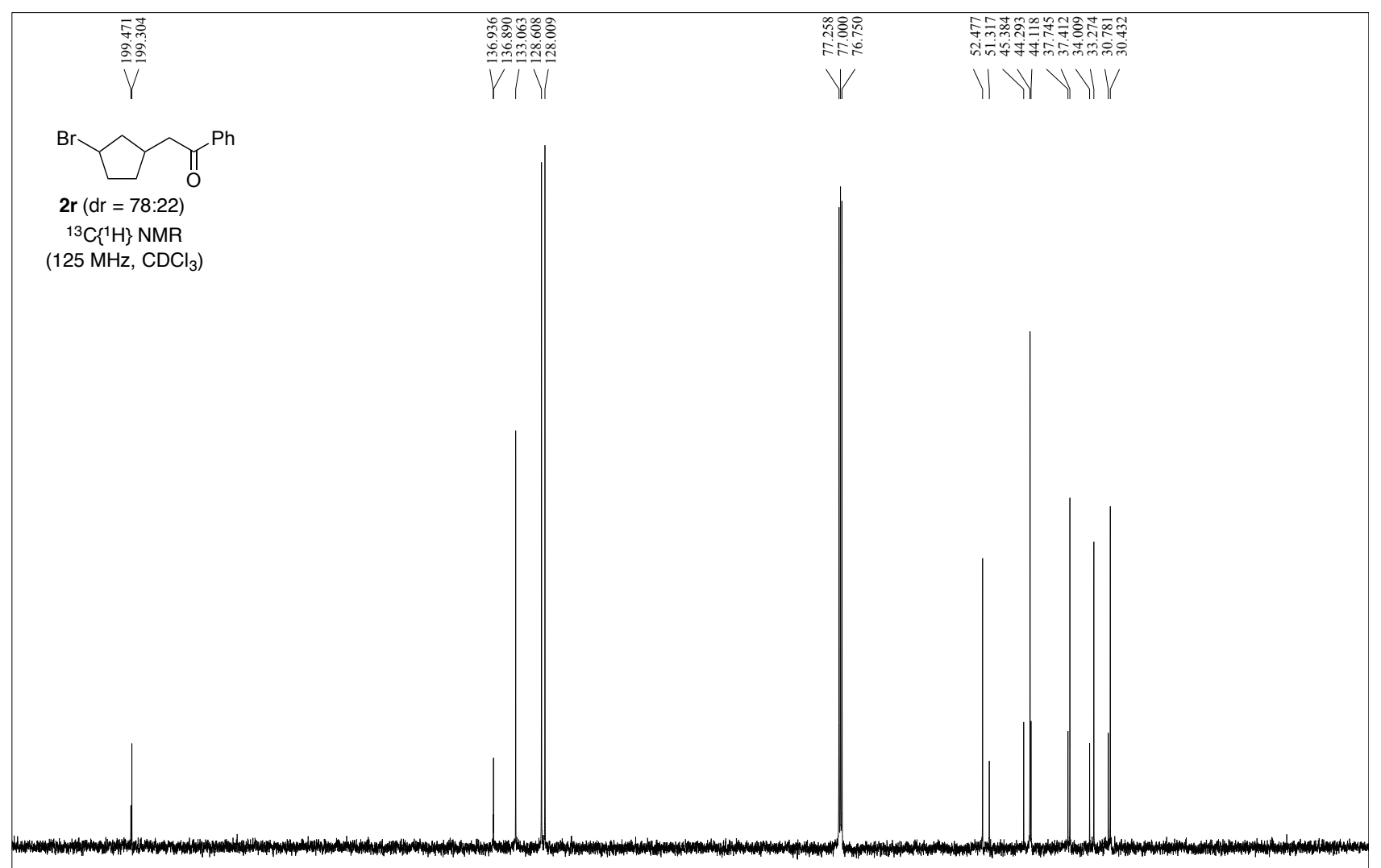

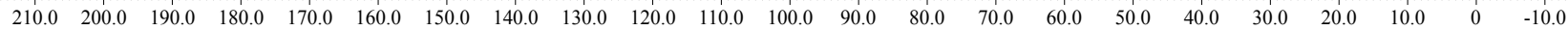
$\mathrm{X}$ : parts per Million : $13 \mathrm{C}$ 


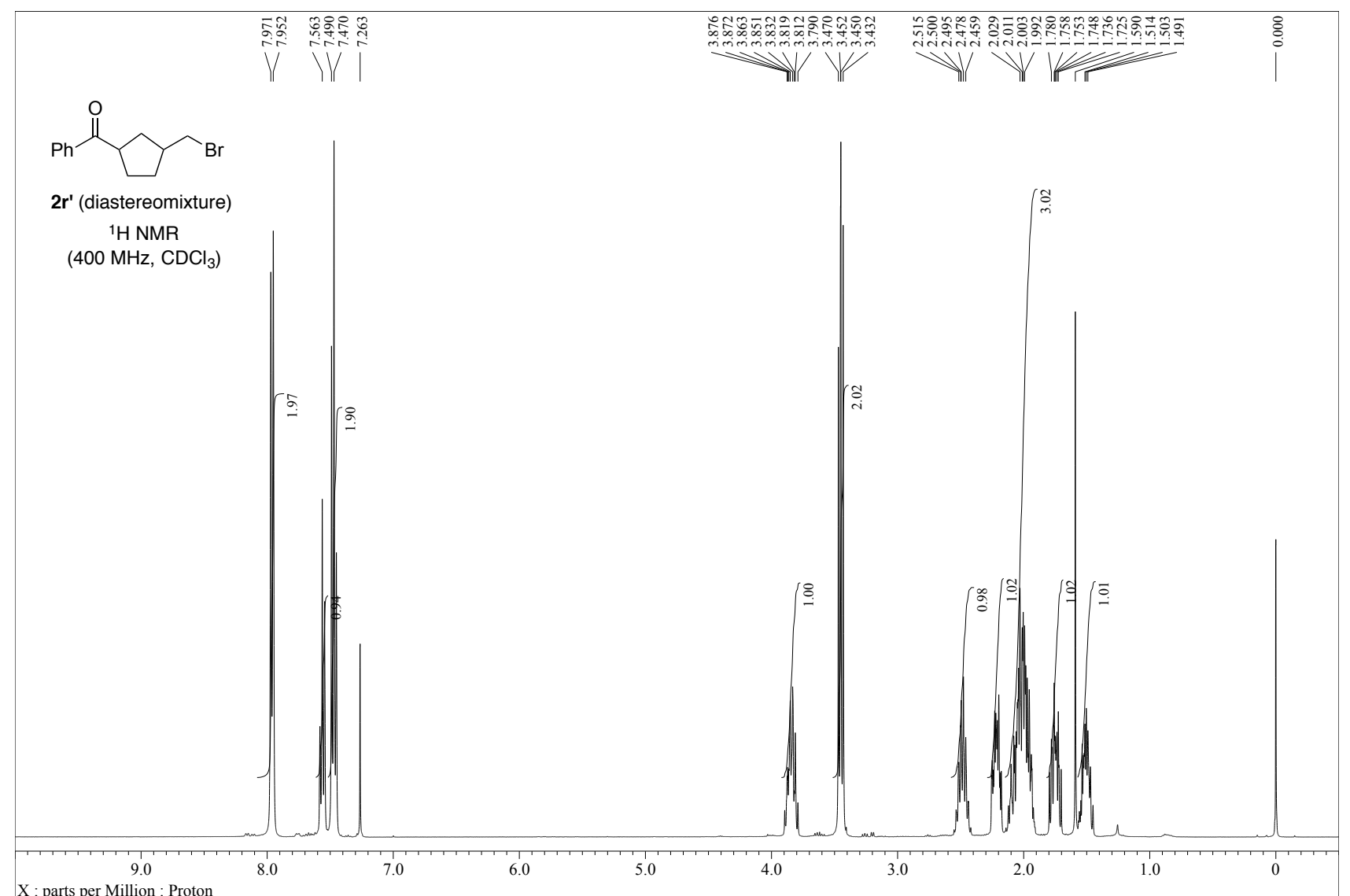

$\mathrm{X}$ : parts per Million : Proton

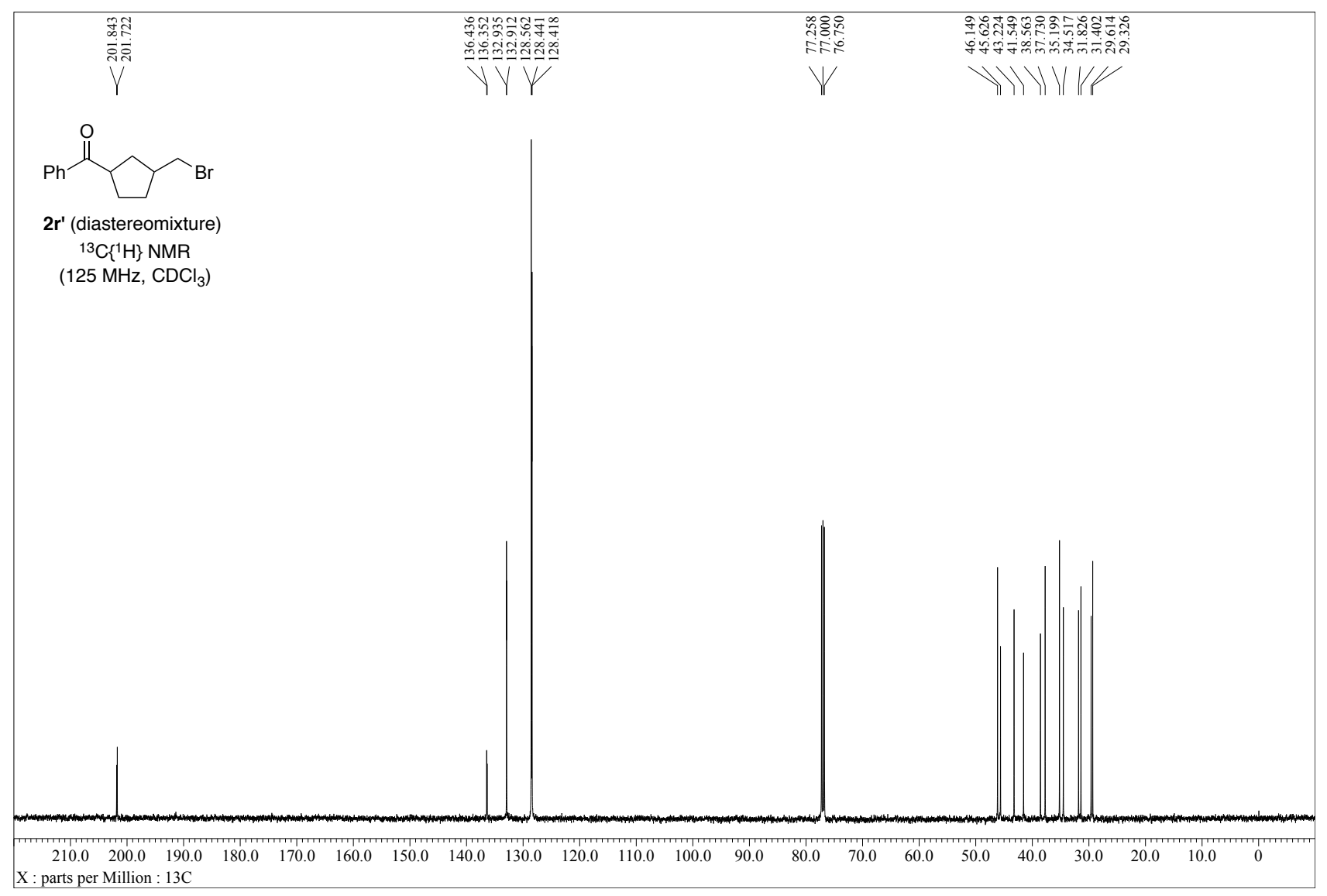




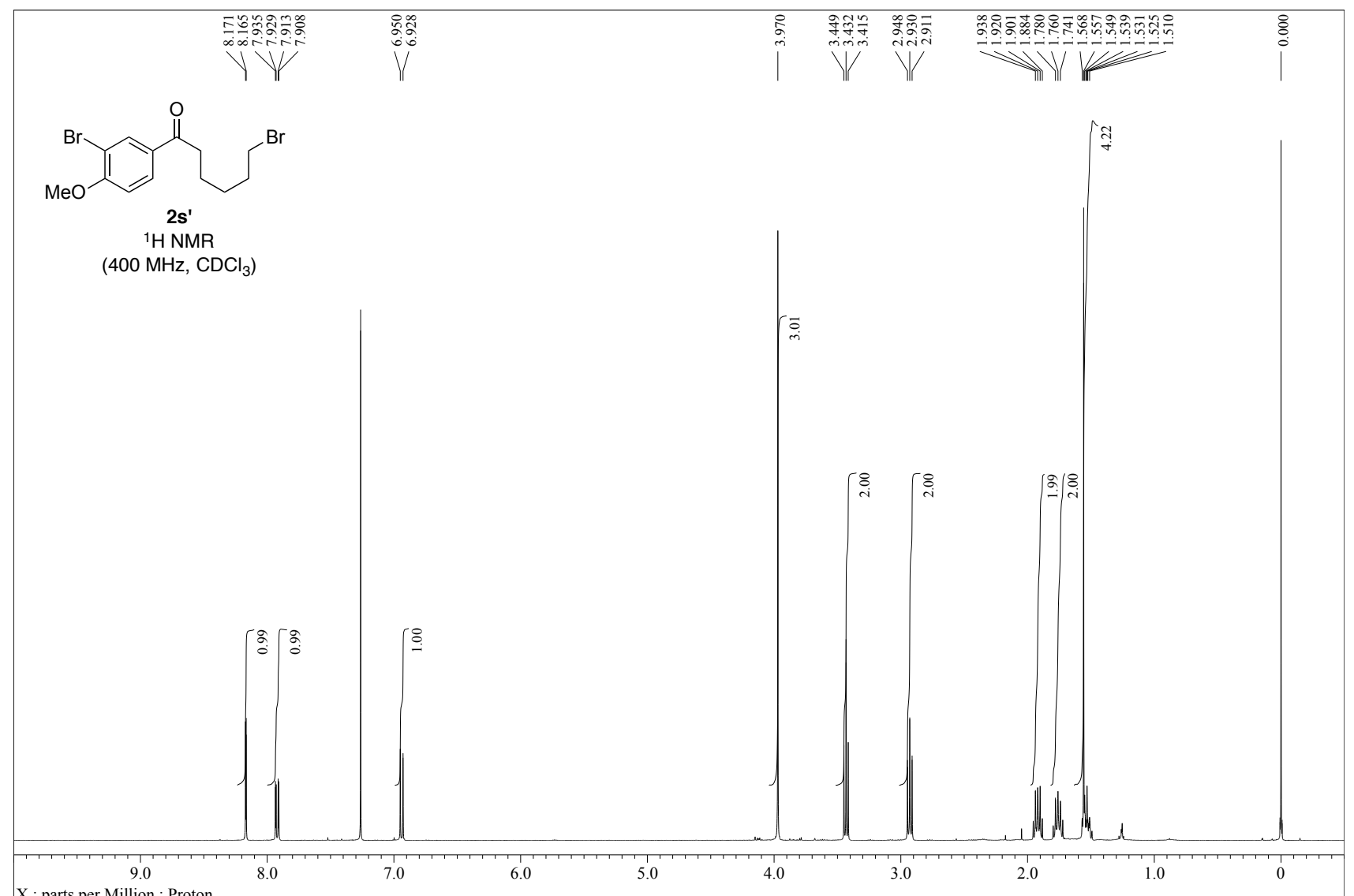

$\mathrm{X}$ : parts per Million : Proton

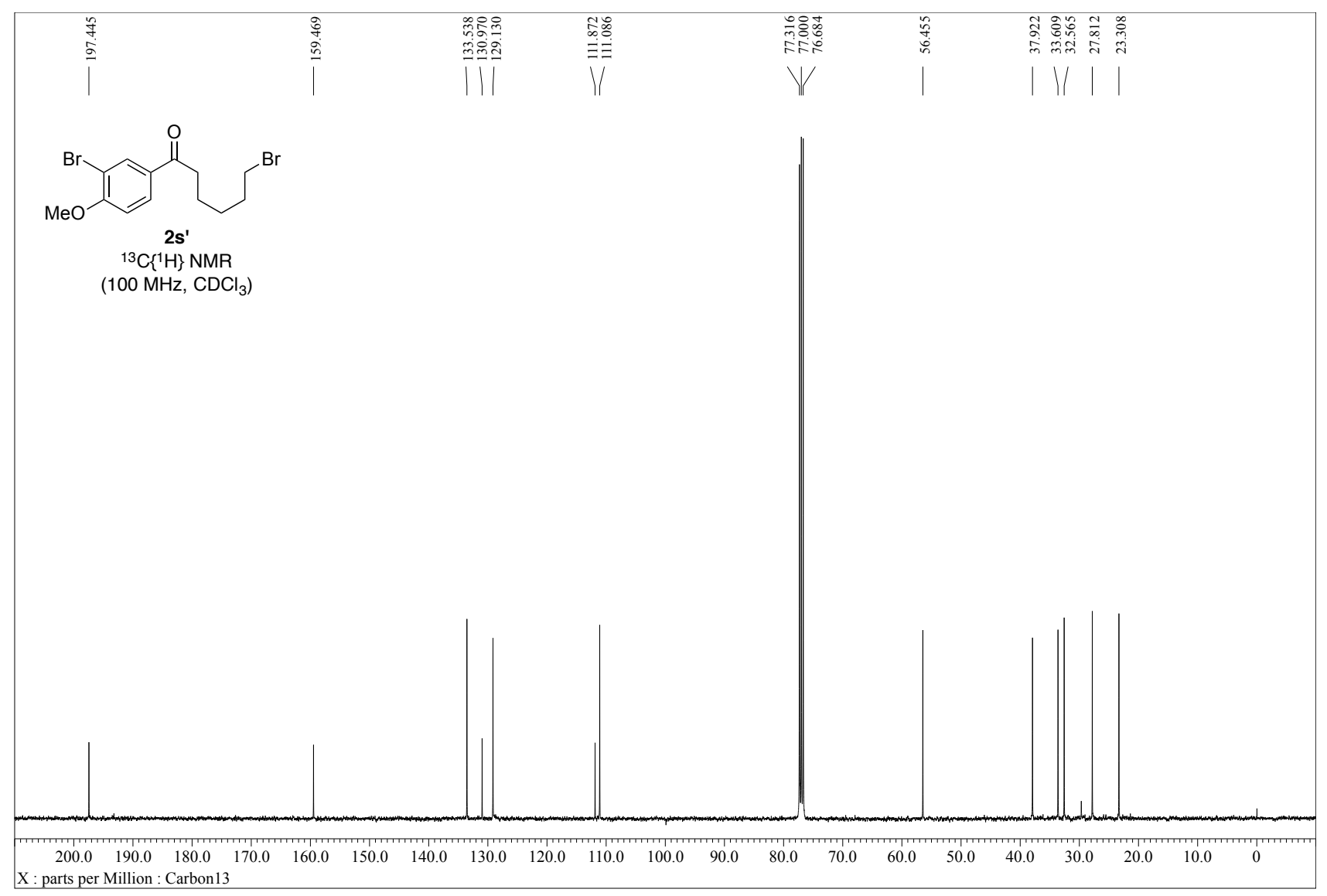



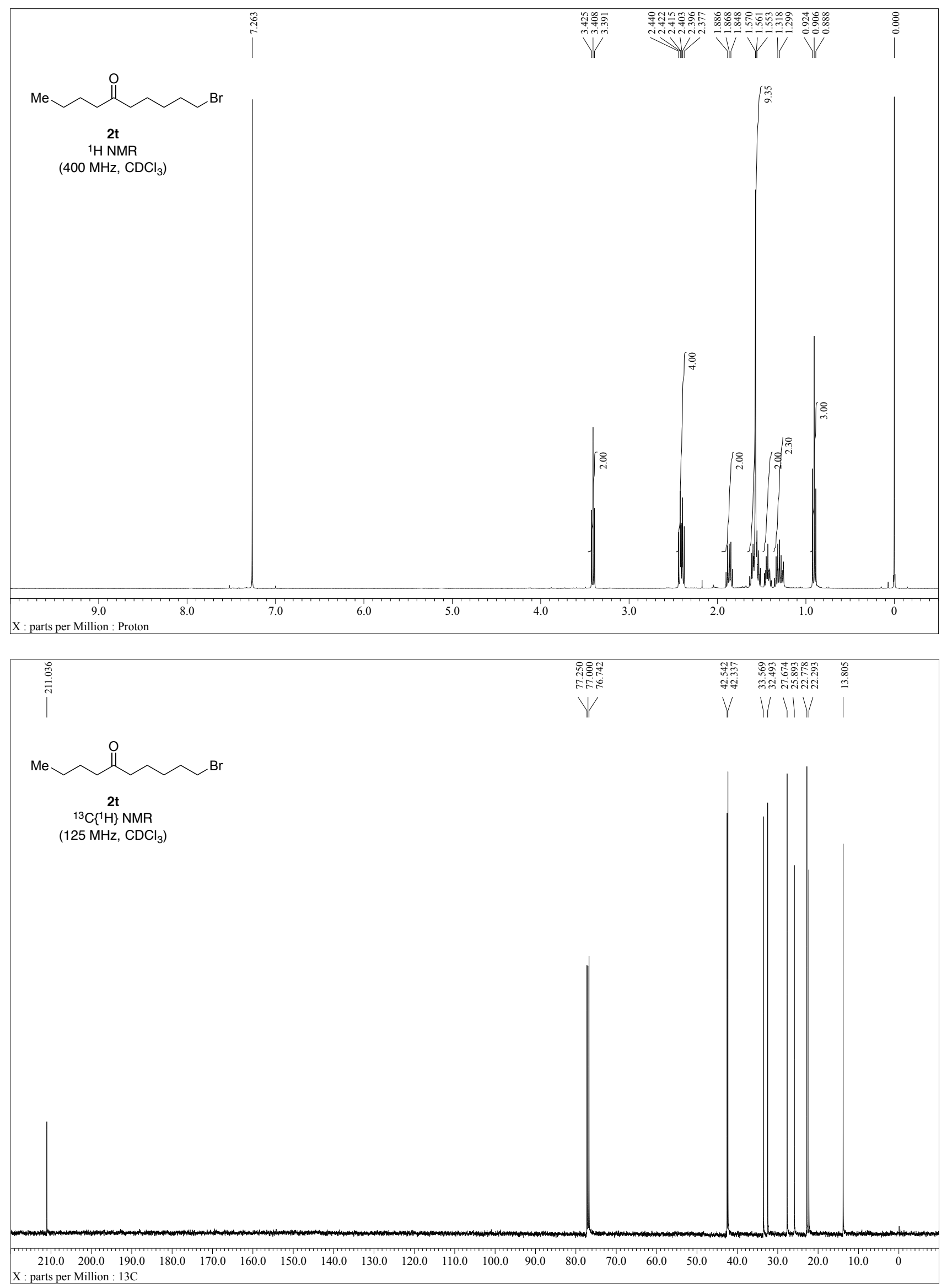

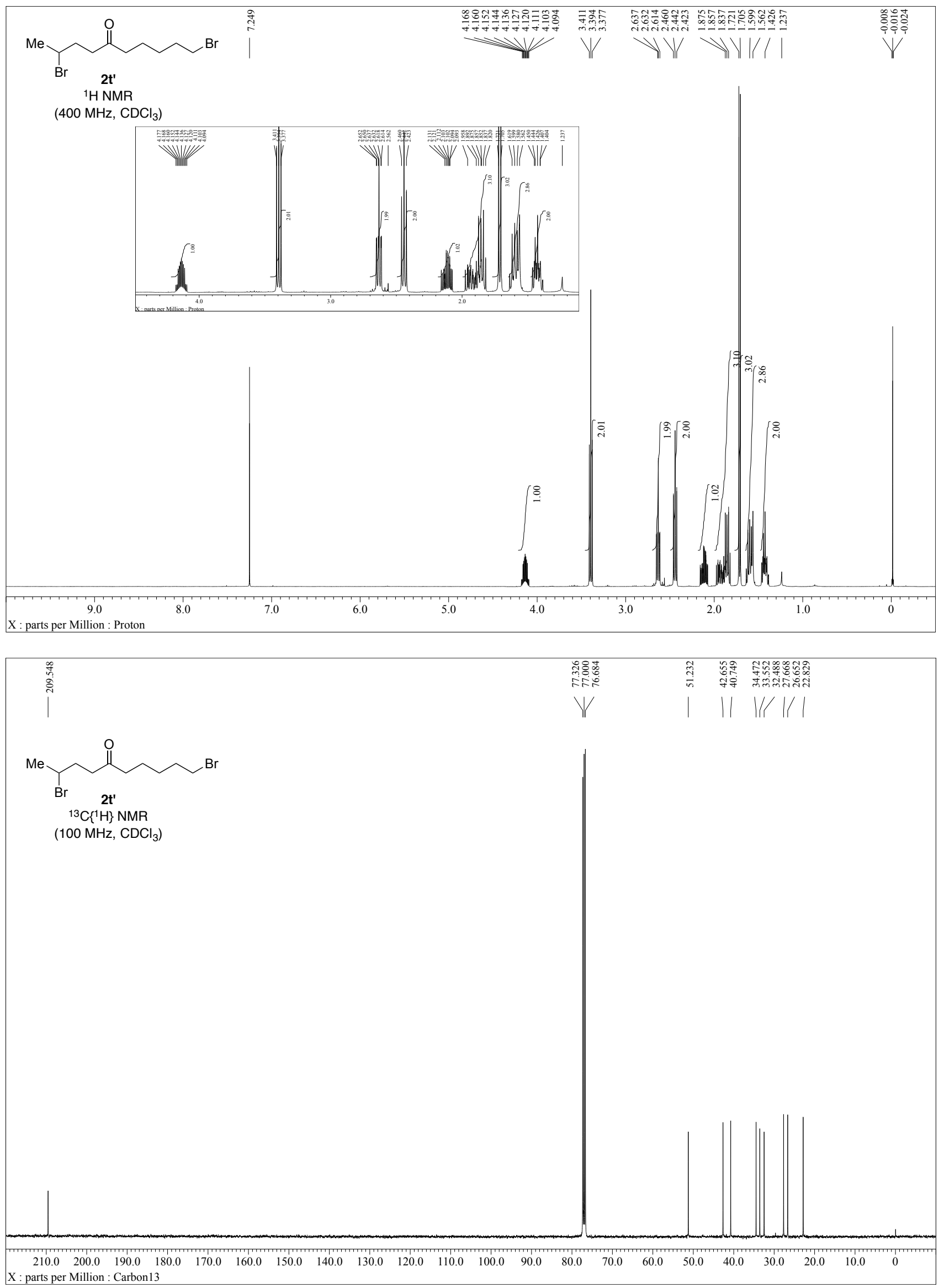

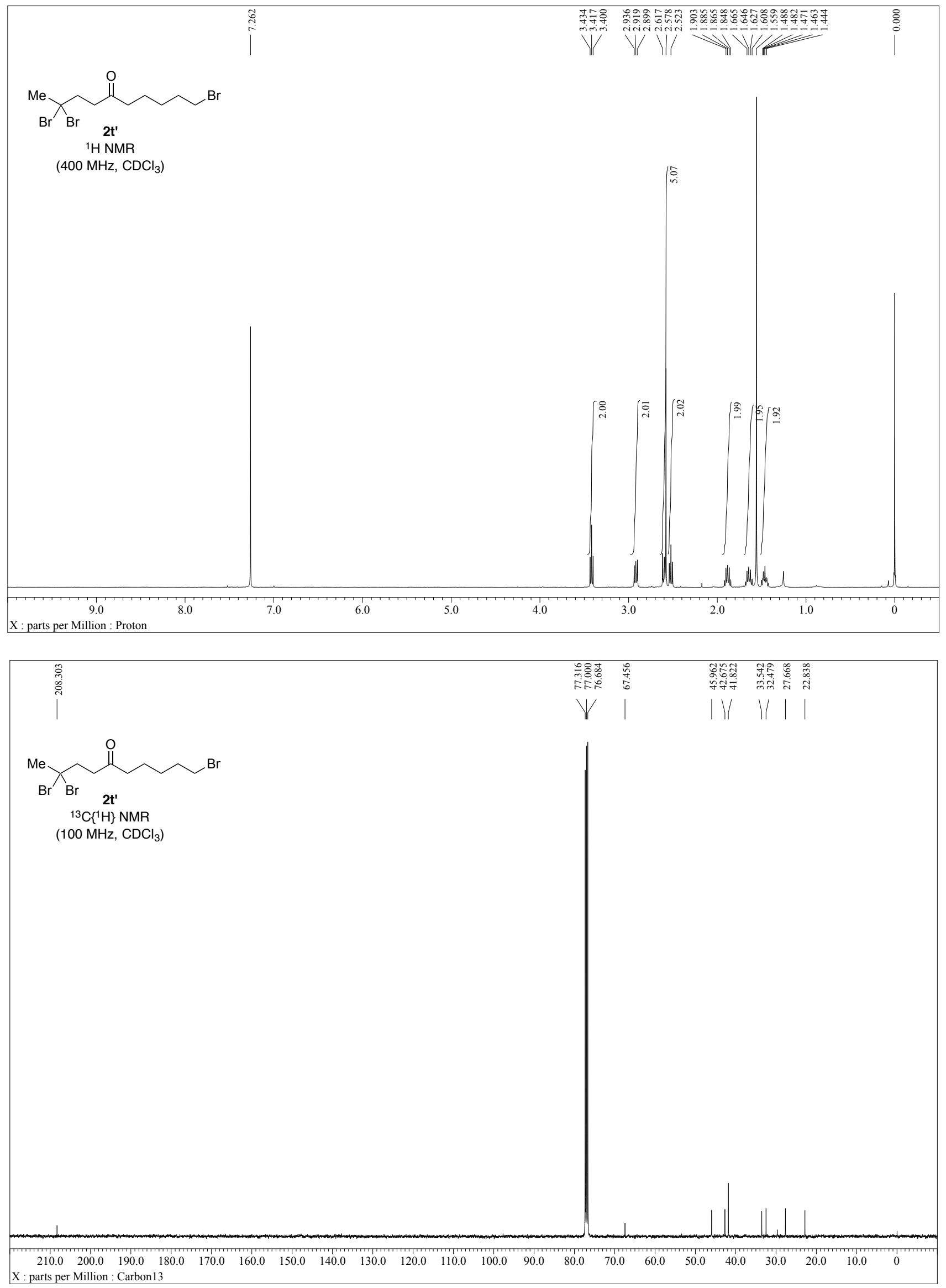